\title{
Review of Fiber Optic Diagnostic Techniques for Power Transformers
}

\author{
Janvier Sylvestre $N^{\prime}$ cho ${ }^{1}$ (D) and Issouf Fofana ${ }^{2, *(D)}$ \\ 1 Département Génie Électrique et Électronique, Institut National Polytechnique Houphouët \\ Boigny (INP-HB), BP 1093 Yamoussoukro, Cote D’Ivoire; janvier.ncho@inphb.ci \\ 2 Research Chair on the Aging of Power Network Infrastructure (ViAHT), Université du Québec à Chicoutimi, \\ 555 Boulevard de l'Université, Chicoutimi, QC G7H 2B1, Canada \\ * Correspondence: issouf_fofana@uqac.ca; Tel.: +1-418-545-5011; Fax: +1-418-545-5012
}

Received: 6 March 2020; Accepted: 6 April 2020; Published: 8 April 2020

check for updates

\begin{abstract}
Diagnostic and condition monitoring of power transformers are key actions to guarantee their safe operation. The subsequent benefits include reduced service interruptions and economic losses associated with their unavailability. Conventional test methods developed for the condition assessment of power transformers have certain limitations. To overcome such problems, fiber optic-based sensors for monitoring the condition of transformers have been developed. Flawlessly built-up fiber optic-based sensors provide online and offline assessment of various parameters like temperature, moisture, partial discharges, gas analyses, vibration, winding deformation, and oil levels, which are based on different sensing principles. In this paper a variety and assessment of different fiber optic-based diagnostic techniques for monitoring power transformers are discussed. It includes significant tutorial elements as well as some analyses.
\end{abstract}

Keywords: power transformer; fiber optic sensor; diagnostic and monitoring

\section{Introduction}

Power transformers, among the foremost expensive equipment of power grids, are essential to the reliable delivery of electricity in the network. As they age, the risk of power grid failure increases. So, condition monitoring is a key to lower unexpected downtime and augment power availability. To be successful, condition monitoring systems must have the capacity to detect gradual or sudden deterioration, as well as trends. It should also be capable to predict allowing sufficient time for proper intervention before major failure. Suitable condition monitoring is predictable and does not compromise the integrity of the system. It also should not require undue maintenance and be cost-effective. Hence, one method to prevent service-aged transformers from causing uncontrolled outages would be to continuously monitor changes in the electrical insulation system. Many methods are currently available for transformer monitoring [1,2]. Conventional test methods typically use electrical sensors or chemical analysis for evaluating transformer condition. However, these methods have important defects concerning real-time measurements due to high electromagnetic interference or high time consumption [3]. Some typical examples are shown in Figure 1 [4].

To overcome such problems, fiber optic-based sensors that allow assessing the condition of the transformers have emerged. In the past decades, fiber optic devices were used to measure optical absorption, fluorescence refractive index, pressure, and strain. Actually, they are increasingly being used in structural health monitoring, but also have many uses in chemical sensing. A large number of different measurable variables can be monitored on-line. For data acquisition, sensors are connected to a monitoring module, where the analogue signals are digitized before being sent to a monitoring 
server [5]. In this contribution, a review of the state-of-the-art concerning the application of fiber optic-based sensors in power transformer monitoring is provided.

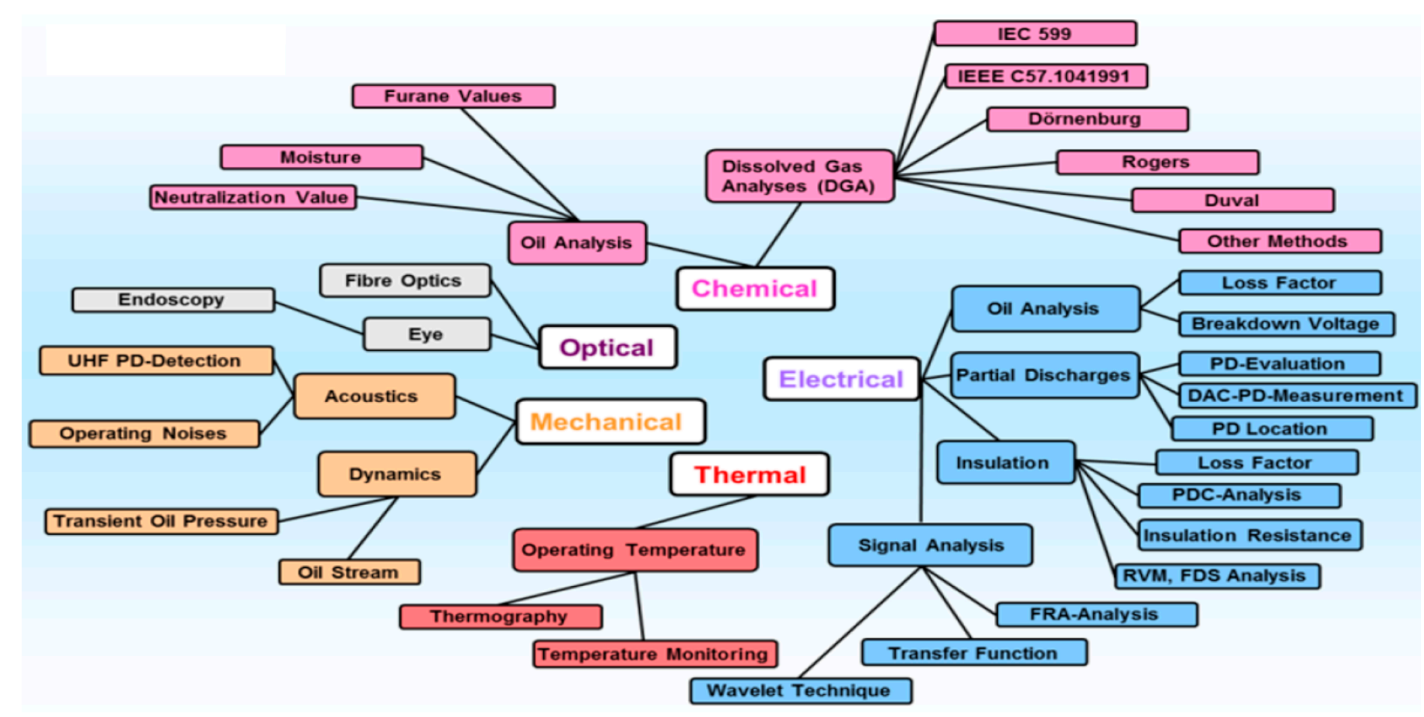

Figure 1. Examples of monitoring and diagnostic methods for evaluating the condition of an oil-filled power transformer [4].

\section{Background on Fiber Optic Sensors}

An optical fiber is basically a cylindrical symmetric structure comprising a central "core" with a 4 to $600 \mu \mathrm{m}$ diameter between and characterized by a uniform refractive index [6]. An optical cladding with a relatively low refractive index then surrounds the optical fiber. The light waves carried in the core by reflection at the interface between the core and the optical cladding are thus trapped [7]. An external plastic coating is used to cover the cladding, providing environmental and mechanical protection to the fiber. Fundamentally, an optical source coupled to a fiber optic transmission line constitutes the fiber optic sensors. This source directs the radiation towards the head of a sensor [8]. As the medium is optics, i.e., light, no electronics is required in the long-range transmission of sensor data, hence their viability for remote sensing applications. An optical fiber sensor comprises the following elements: an optical fiber, a sensing component, a detector, and a light source. It operates in such a way that some parameter of the optical system (wavelength, phase, polarization, intensity, etc.) intensity is modulated by the sensing element, which produces a change in the characteristics of the optical signal at the detector. The main idea is to measure an external physical parameter by inducing changes in one or more of the optical properties of the light beam travelling inside the optical fiber [9]. So, the fiber is simultaneously the transmission medium and the sensing element. Fiber optic sensors are classified as intrinsic or extrinsic according to their location [10]. If the modulation occurs in the fiber, it is intrinsic. It is considered extrinsic if the modulation is made through an external transducer.

Based on operating principles, fiber optic sensors can be classified into the following five categories [11,12]:

- Phase-modulated sensors precisely measuring the phase of light difference in a sensing fiber to a reference fiber using an interferometer. Although much more expensive, phase-modulated sensors are more accurate and have a much larger dynamic range than intensity-modulated sensors. The most commonly used interferometers are Mach-Zehnder, Michelson, Sagnac, polarimetric, and grating interferometers.

- Intensity-modulated sensors are usually used for displacement or other physical changes interacting with the fiber or a mechanical transducer attached to it. The received light is modified by these changes, allowing measurement of the phenomenon. 
- Wavelength-modulated sensors that experience wavelength change associated with displacement, temperature, or the presence of chemical species, which causes fluorescence.

- Scattering-based sensors that are associated with three types of light scattering: Rayleigh, Raman, and Brillouin. Anomalies along the fiber are detected by changes in the scattered light back-reflected along the fiber to a detector that is incorporated into a form of optical time-domain reflectometer. The perturbation of the scattered light may cause an intensity change or wavelength shift caused by the parameter being sensed, typically temperature or strain.

- Polarization-based sensors that are based on phenomena such as Faraday rotation or birefringence that can alter the polarization state, hence altering the intensity of the transmitted light.

Fiber optic sensors can be categorized as either single point, multipoint or distributed, according to their configuration and topology. The choice of classification mainly depends on the application and the measurement method. Usually, single-mode fibers are associated with intrinsic optical fiber sensors (e.g., interferometry methods), but multimode fibers are associated with extrinsic sensor systems and transmit the light to and from the sensor head [8]. Figure 2 summarizes the classification of fiber optic sensors.

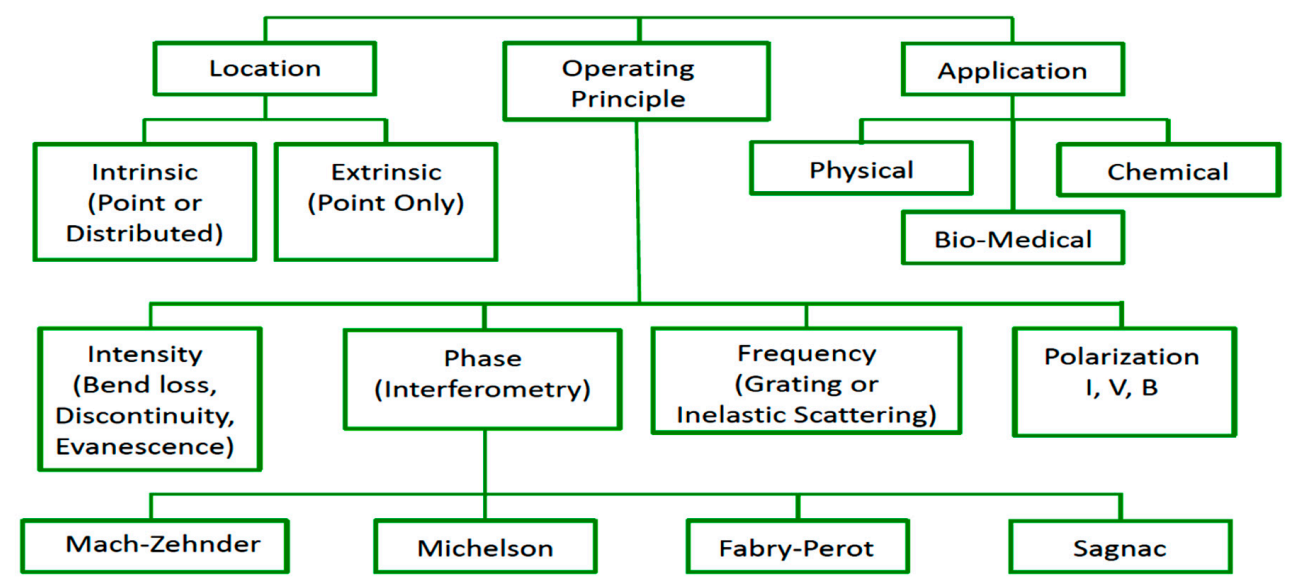

Figure 2. Classification of fiber optic sensors.

Fiber optic sensors have proven to be useful for measuring a wide variety of important parameters for systems and components in power plants and electrical grids. Initial interest for fiber optic sensors on markets has been motivated by greater performance and other advantages. Some of these difference as compared to conventional electronic sensors are listed in Table 1 [11,13-15].

Table 1. Advantages of fiber optic sensors.

\begin{tabular}{c}
\hline Passive (All Dielectric) \\
\hline Capable of measuring multiple parameters with high sensitivity \\
High temperature performance \\
Small size (100-500 $\mu$ m diameter optical fiber) and lightweight \\
No interference from radio frequency (RFI) and electromagnetic waves (EMI) \\
Large bandwidth \\
Potentially easy to install \\
Allow for remote and distributed sensing \\
Can function in harsh environments \\
Solid state reliability \\
Secure data transmission \\
Resistant to ionizing radiation \\
Can be interfaced with data communication systems \\
Non-electrical \\
Explosion proof
\end{tabular}


Recently, fiber optics based on nanofilms have emerged. All together, fiber optics with nanostructure technologies and sensitive thin films offers attractive opportunities for making novel sensors. Optical fiber serves as a signal carrier, while the thin films work as sensitive elements and transducers to collect responses and feedback from the environment. The main features of nanofilm-based fiber optics are listed as follows [16]:

- An evanescent wave is characterized as an oscillating electric and/or magnetic field whose energy is spatially concentrated in the vicinity of the source (oscillating charges and currents) but does not behave as an electromagnetic wave in terms of propagation.

- A micro-mirror is generated by a nanofilm deposited on the polished fiber-tip.

- Fiber Bragg grating (FBG) reflects particular wavelengths of light and transmits all others by means of a distributed reflector located in a short segment of optical fiber. Generating a wavelength-specific dielectric mirror is done by creating a periodic variation in the refractive index of the fiber core.

- Micro-structured fiber, also called photonic crystal fiber (PCF), is a new type of optical fiber based on the properties of photonic crystals.

- Micro-machined fiber is micro-treated by other techniques, including side-polishing laser micromachining and chemical etching.

Examples of thin films or coatings can be found in [16].

\section{Fiber Optic Sensor for Electrical Parameters Assessment}

\subsection{Partial Discharges}

Partial discharges (PDs) are partial electrical breakdowns in weak regions of an electrical insulation system. Generally, there are two different types of partial discharges occurring in a transformer [17]:

- $\quad$ PDs of the corona type: In transformer insulation systems, these discharges occur in gas bubbles suspended in oil where gas is ionized in cold plasma at a low (ambient) temperature; this process produces mostly hydrogen $\left(\mathrm{H}_{2}\right)$ together with some methane $\left(\mathrm{CH}_{4}\right)$ and will not damage or carbonize the paper insulation. A PD of the corona type is also used to describe discharges into air or gas at the terminals of the tested transformers (if shielding electrodes are not used).

- PDs of the sparking type occur in the liquid (oil) or solid (paper) phases. Such PDs are small arcs and their temperature is very high $\left(>3000^{\circ} \mathrm{C}\right)$. They produce mostly acetylene $\left(\mathrm{C}_{2} \mathrm{H}_{2}\right)$ and hydrogen $\left(\mathrm{H}_{2}\right)$ and may degrade the paper insulation (carbonized pinholes, tracking) and oil (decay products, dissolved gases in oil).

- PDs of the surface type: This type of discharge takes place on the outer surface of a solid insulation. This discharge occurs at the interface of two different insulation materials, which offer the lowest dielectric strength, especially if the two-insulation joint surface is placed in the direction of the force lines and electric field. This phenomenon may be exacerbated by space charge accumulation.

An overview of the physical effects of permanent PD activity and of techniques of detection are shown in Figure 3.

The ultra-high-frequency (UHF) PD detection method has become an attractive research topic due to its high sensitivity, high anti-interference capacity, good reliability, and capacity to recognize and locate discharge sources [18]. Unfortunately, such methods are affected by electromagnetic interference and may be a source of pollution for the power grid and equipment [19]. Therefore, non-electrical measurement methods are gradually attracting more attention, because they are not prone to electromagnetic interference. Concerning optical fibers for detection of partial discharge, there are two main types of technology [20,21]:

- Fiber optic interferometers (Michelson, Fabry-Perot, Sagnac, and Mach-Zehnder) are suitable for partial discharge monitoring by detecting acoustic emission signals. 
- $\quad$ Fiber Bragg grating (FBG) sensors with smaller size and stronger multiplexing capability are an alternative choice but with lower sensitivity than interferometers.

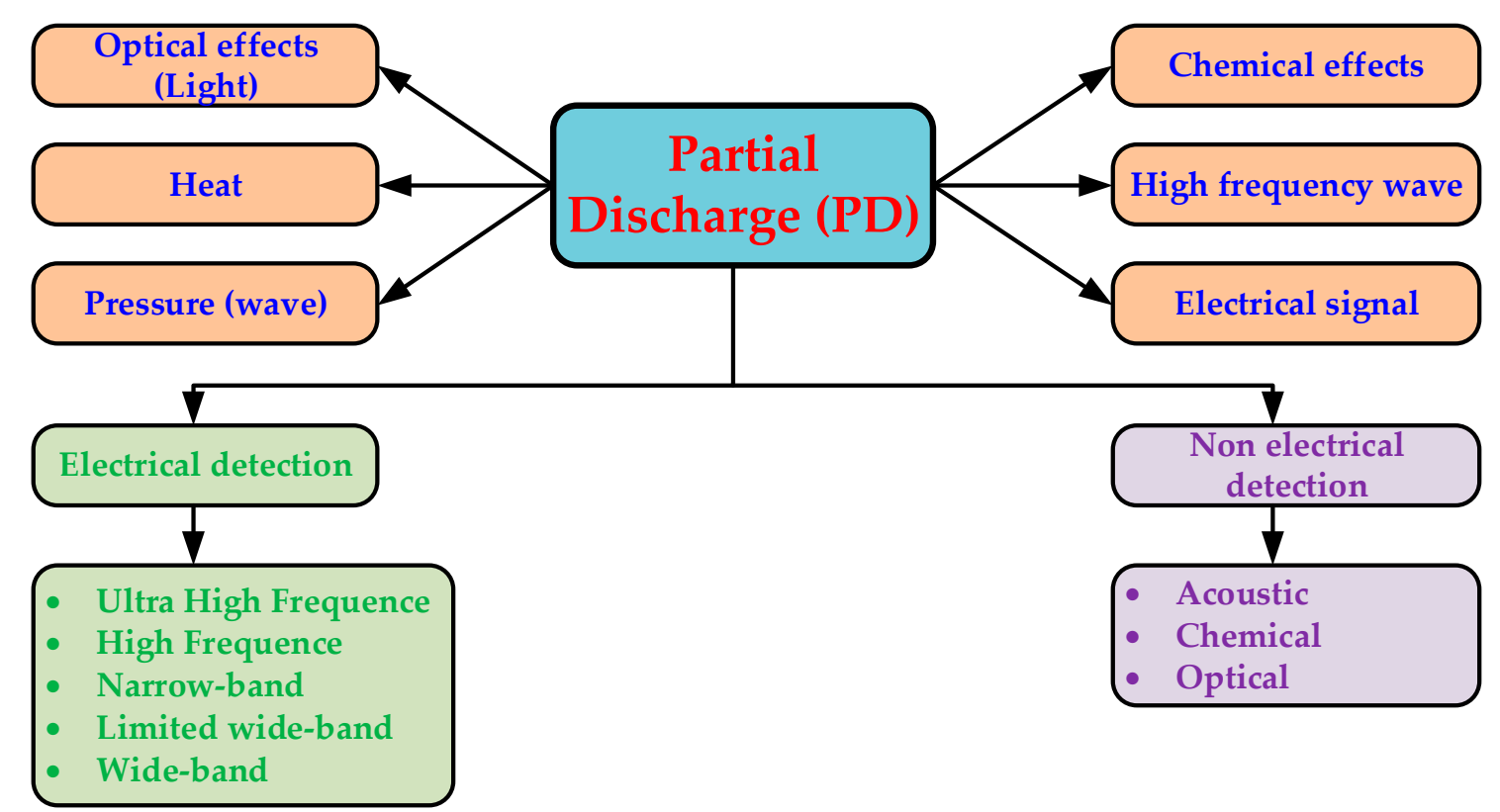

Figure 3. Overview of the physical effects from partial discharge (PD) activities.

Depending on their structure, these sensors have different sensing performances (as to sensitivity and frequency response), and are applied in different ways, like placed inside or outside transformers, or both [19]. Fiber optic interferometers have high sensitivity and a large flat response range but are difficult to multiplex. Following the IEEE Std C57.127 [22], the frequency range of PD acoustic emission is $20-500 \mathrm{kHz}$.

Chen et al. [23] made an extrinsic fiber Fabry-Perot (FP) sensor for detecting PD acoustic emission. The results showed that this sensor can detect PD acoustic emissions for both wideband and narrowband modes. Furthermore, this sensor reached a higher sensitivity in the narrowband mode. The experimental results showed that PD acoustic emission is characterized by high amplitudes in the $50-170 \mathrm{kHz}$ frequency range.

Wang et al. [19] presented an optical fiber sensing probe to detect the ultrasonic signals of PD based on linear Sagnac optical interferometry. As was experimentally shown, the PD signals had a time-domain amplitude range of $0.8-1.9 \mathrm{~V}$, and a frequency response range up to $58 \mathrm{kHz}$, with a $10 \mathrm{kV}$ voltage.

For acoustic emission from partial discharges to be detected in power transformers, Zhou et al. [24] proposed a Michelson ultrasonic sensor. The sensitivity of the proposed system increases when the fiber coil gets smaller in the $80-200 \mathrm{kHz}$ frequency range. A detection limit of about $0.26 \mathrm{~Pa}$ was observed when the distance between the sensor's head and the ultrasonic source was $300 \mathrm{~mm}$ in the oil.

Two FBGs and a Teflon mandrel were combined by Ghorat et al. [21], to double the sensitivity of the FBG. The two FBGs were used in the transmission and reflection modes. The sensor had few resonant frequencies and the favorable detection range was around $53 \mathrm{kHz}$. The direction dependence was less than $0.4 \mathrm{mV}$, which was acceptable for PD localization.

For the same goal, to improve the zirconate titanate (PZT) sensor, Ma et al. [25] presented a new PD detection system based on phase-shifted fiber Bragg gratings (PS-FBG). Experimental results on frequency response showed that the PS-FBG sensitivity was $8.46 \mathrm{~dB}$ higher than the conventional ultrasonic sensor. A PD detection indicated that the PD sensitivity of the PS-FBG immersed in oil is 17.5 times higher than that of the PZT sensor. 
Based on the understanding of wave propagation, a novel structure of fiber optic acoustic sensors array was developed and installed into a real $35 \mathrm{kV}$ transformer [26]. A novel way to obtain accurate online PD localization was enabled by this sensor for power transformers, especially for PD events occurring inside windings or in the oil ducts between windings. Experimental testing indicated that PD localization with less than $5 \mathrm{~cm}$ error was achievable using this design.

\subsection{Electrical Breakdown Assessment}

The dielectric strength or breakdown voltage of transformer oil measures its capacity to support electrical stress without failure. Since these oils should ensure insulation under high electrical potentials, it means that a significant reduction in dielectric strength will indicate the oil is no longer able to perform. A reduction in dielectric strength can be caused by the presence of contaminants, such as water, conducting particles, oil degradation by-products, sediments, and cellulose paper breakdown $[27,28]$. Dielectric strength can be determined relatively simply by applying an AC voltage at an increasing rate between two electrodes immersed in the transformer oil. It is important to early detect breakdown occurrence in transformer oil as it helps to further assess transformer health condition and prevent further deterioration in the transformer. In [29], a fiber optic-based sensor using a step index multimode polymer optical fiber was developed to monitor transformer oil breakdown. The polymer optical fiber sensor was placed inside a testing tank, keeping the unclad portion immersed in the transformer oil. The principle of measuring the breakdown voltage represented by the output voltage of the optical fiber is directly related to the refractive index of the transformer oil. The intensity of the light flux of the optical fiber sensor is modified by the change in the refractive index of the oil. It has been shown that the refractive index for a service-aged oil is higher than for a new oil [30]. When the oil degrades, the breakdown voltage decreases as the refractive index increases. The output voltage of the optical fiber, which is immersed in oil, will increase or decrease with the level of oil contamination, indicating that the oil is new or aged, respectively.

\subsection{Current and Voltage Monitoring}

Instrument transformers (current and voltage transformers) are extensively used in substations to measure and monitor current and voltage. These measurements are essential to maintain operating and protecting functions in the substation, since it is important for transformer voltage and current transformers to be reliable and accurate. Fiber optic-based current and voltage sensors depict lot of advantages over conventional instrument transformers and dividers [31]. Using sensors for the measurement of voltages and currents in a distribution system is beneficial to many key applications with other benefits like better energy efficiency, improved reliability, higher power quality, lower maintenance costs, and increased operational awareness [32].

Fiber optics current sensors are based on magnetic field-induced circular birefringence (Faraday effect). The fiber itself behaves like a transducer. The rotation of the polarization angle of the light propagating in the fiber-which is proportional to the magnetic field-is rendered possible by the magneto-optical effect. Two principal detection procedures that can be used to measure the Faraday rotation of the azimuth output light are polarimetry and interferometry [33]. In general, the fiber is coiled around the conductor, so that it is not influenced by external currents and magnetic fields [33]. The sensor's sensibility also can be adjusted by simply changing the number of turns of the optical fiber around the conductor or by adding dopants to the core [33]. The fibers are typically single-mode silica fibers with no need of alignment or precision matching.

The fiber optic voltage sensors are based on the electric field induced linear birefringence (Pockels effect) in electro-optical crystals, or the converse piezoelectric effect in a cylinder-shaped quartz crystal. Voltage measurement is performed through light transmission through optical fibers that bring inherent immunity from electromagnetic interference and is compatible with low voltage analog and digital equipment used for metering and relaying applications [34]. Under the influence of an electric field, their refractive index of electro-optic materials, usually crystals, changes. The consequence of a 
variation in the refractive index is to induce a change in the phase of the light beam passing through the crystal. This modification in phase also affects the polarization of the beam. Typical crystals depicting a Pockels effect are potassium dihydrogen phosphate (KDP), lithium niobate $\left(\mathrm{LiNbO}_{3}\right)$, bismuth silicon oxide $\mathrm{Bi}_{12} \mathrm{SiO}_{20}$ (BSO), bismuth titanate $\mathrm{Bi}_{12} \mathrm{TiO}_{20}$ (BTO), and bismuth germanate $\mathrm{Bi}_{4} \mathrm{Ge}_{3} \mathrm{O}_{12}$ (BGO) [34]. The frequently used BGO crystals are known for their stable behavior for at least one hour, even under DC operation [35].

Figures 4 and 5 present an overview of the current- and voltage-related sensor technology in the power industry [36].

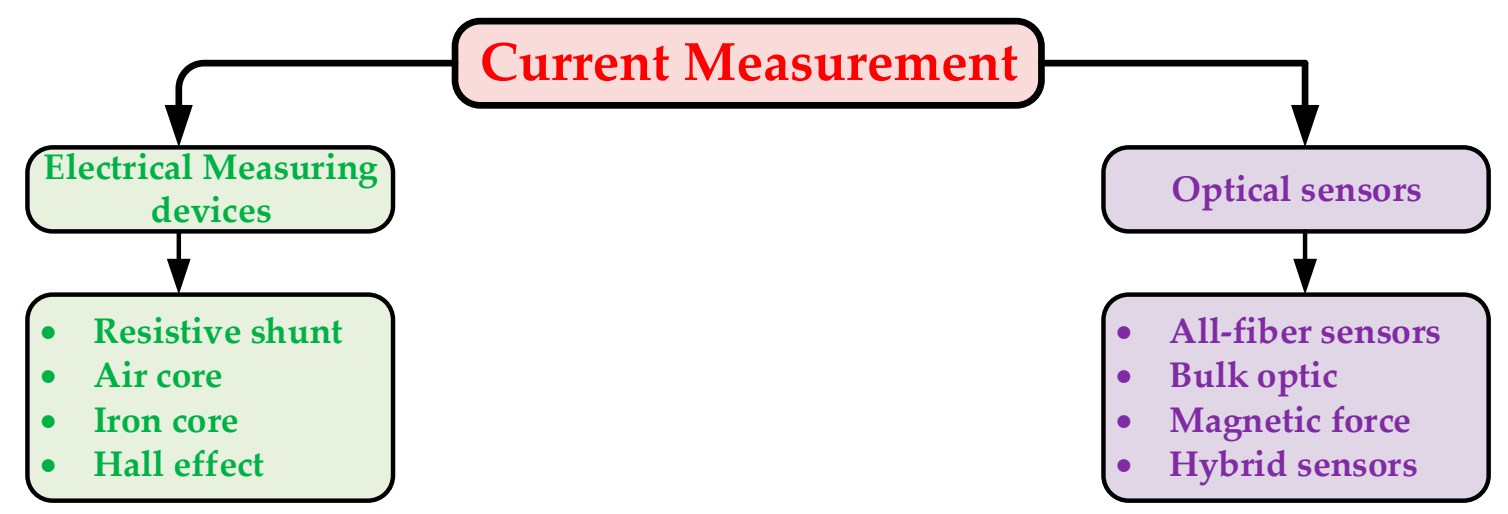

Figure 4. Classification of current sensor technologies.

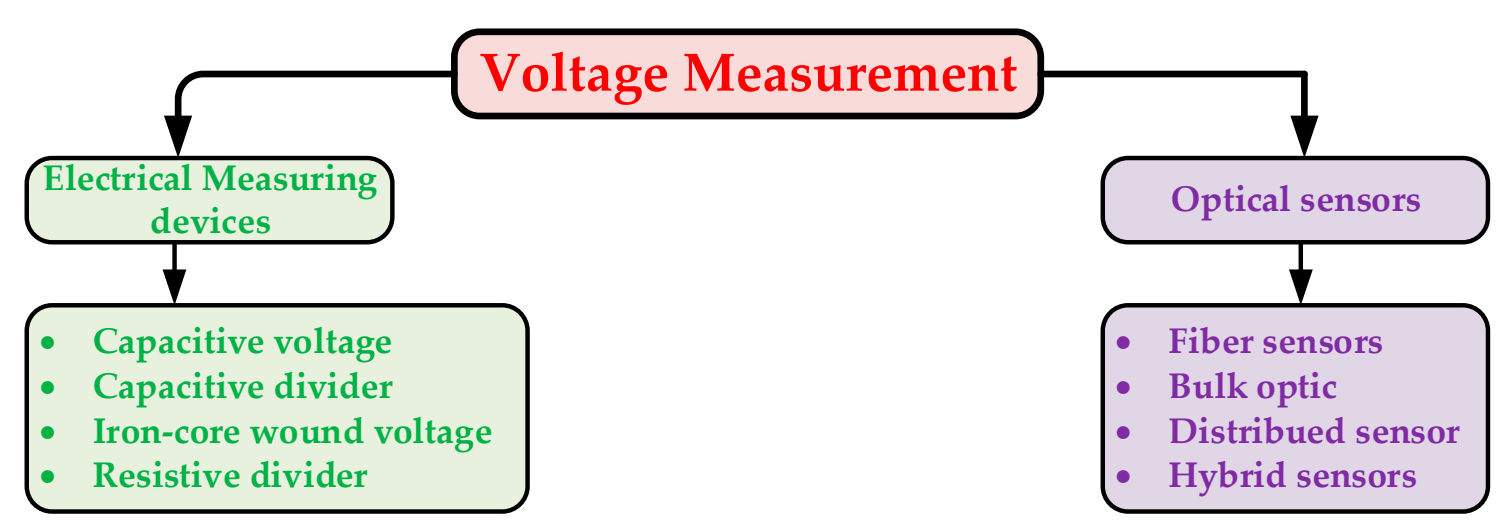

Figure 5. Classification of voltage sensor technologies.

Huang et al. [37] used an all-fiber optical current transformer for measuring lightning current. With this fiber, the measurable range was over 1-100 kA. The dynamic range was greater than $40 \mathrm{~dB}$ and the measurement error was less than $5 \%$.

To overcome shortcomings of current transformers for current high voltage electric energy meters, Fuli et al. [38] proposed a new $10 \mathrm{kV}$ high voltage meter based on an all-fiber optical current transformer.

Bohnert et al. [39] proposed a polarimetric fiber optic current sensor for power transmission systems. The sensor operated in reflection mode and had an integrated optic polarization splitter (IOPS) for interrogation. Sensor accuracy was demonstrated to be well within $\pm 0.1 \%$ for a cycle time of $200 \mathrm{~h}$ in a temperature range from $-45^{\circ} \mathrm{C}$ to $85^{\circ} \mathrm{C}$. In [40], a fiber sensor voltage transducer, for use in the $500 \mathrm{kV}$ supply network after on-site calibration, was presented. In [41], an electro-optic voltage transducer with BGO crystals $\left(\mathrm{Bi}_{12} \mathrm{GeO}_{20}\right.$ or $\left.\mathrm{Bi}_{4} \mathrm{Ge}_{3} \mathrm{O}_{12}\right)$ in a SF6 atmosphere for use up to the $550 \mathrm{kV}$ level was proposed. A fiber optic voltage sensor array of eight series-connected BGO crystals is described in [35]. This sensor showed excellent linearity. For DC voltages in the range of $\pm 225 \mathrm{kV}$, the deviations are within $\pm 0.2 \%$. For $50 \mathrm{~Hz}$ AC peak voltages up to $250 \mathrm{kV}$, the deviations are in the range of $\pm 0.1 \%$ and $\pm 0.2 \%$ for lightning impulse voltages up to $400 \mathrm{kV}$. 
Inductive current and voltage transformers are known to be reliable technologies. Experience gained so far with optical transducers is inconclusive to assess their accuracy and expected long-term behavior. This is one of the main reasons why their use is not widespread yet [35].

\section{Fiber Optic Sensor for Mechanical Parameters Assessment}

\subsection{Winding Deformation and Vibration}

The sweep frequency response analysis (SFRA) is the main technique for evaluating the geometrical and mechanical integrity of the transformer [42]. Some of the damage occurring in the transformer is caused by high currents during short circuit faults. However, online application is still the aim of investigations in various research groups worldwide. The vibration frequency of the transformers is usually in the range of 100-600 Hz and shows a lot of resonant frequency doubling information [43] but gradually disappear after more than $1000 \mathrm{~Hz}$ [44]. To propose an alternative to online assessment, Kung et al. [45] developed a thin fiber optic sensor for direct winding vibration measurement. This sensor is an extension of the Fabry-Perot fiber optics vibration sensor for monitoring the stator end-winding vibration. The proposed sensor, measures vibration between $20 \mathrm{~Hz}$ to $1000 \mathrm{~Hz}$. Similarly, Min et al. [43] used high-sensitivity FBG vibration sensor to monitor the vibration signal of the transformer during real-time online monitoring. The principle was based on the interference demodulation of the unbalanced Michelson interferometer. There was a fundamental coherence of the monitored signal and that of the piezoelectric sensor in the frequency domain. The frequency response of this sensor was narrow and was within $200 \mathrm{~Hz}$.

Recently, Aguinaldo et al. [46] developed FBG pressure sensors to monitor the static and dynamic pressure in high voltage winding transformers in the advent of short-circuit and inrush current. The FBG deformations were placed at the top or at the base of the transformer windings (Figure 6) [46].

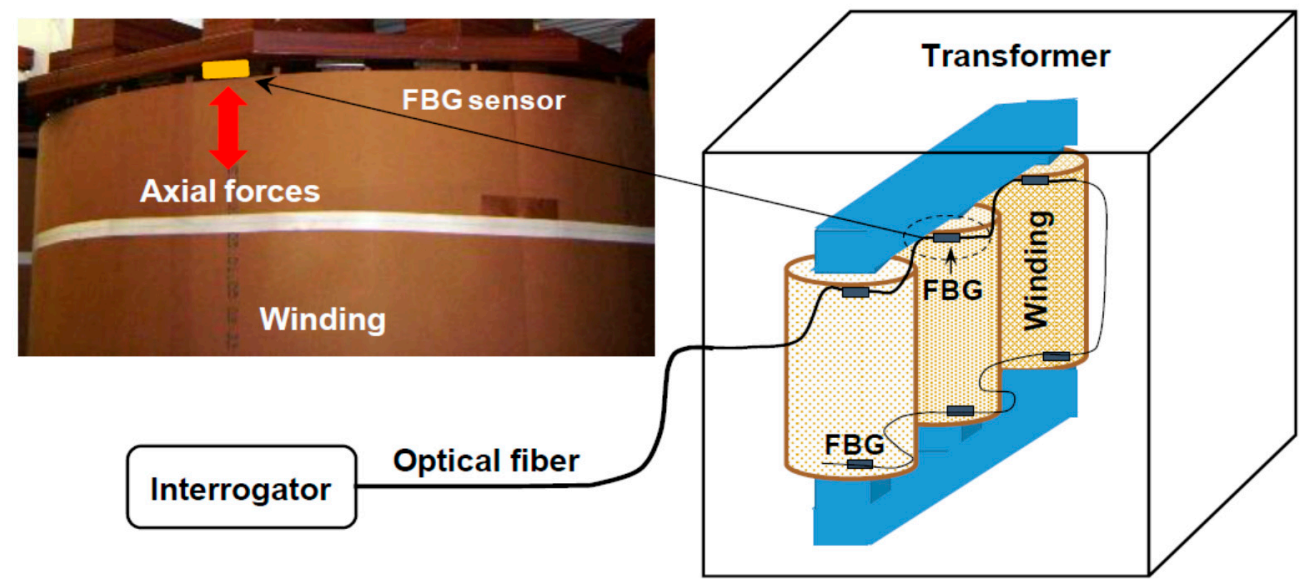

Figure 6. Fiber Bragg grating (FBG) sensor deformations in transformer windings [46].

These sensors were made with two materials, transformer board (TB) and polyether ether ketone (PEEK), and were stressed under usual short circuit winding pressure. The sensor time of response was measured with a $5 \mathrm{kHz}$ interrogation system in order to correctly analyze the response time of the short circuit. The PEEK sensor exhibited better sensitivity than the TB sensor. The static sensitivity obtained with the PEEK-based sensors was $0.911 \mathrm{pm} / \mathrm{N}$, in the range of $800 \mathrm{~N}$ to $1500 \mathrm{~N}$, which is 4.47 times higher than the TB sensors. The dynamic responses of the sensors showed excellent repeatability for both sensors. The sensitivity of the PEEK was up to 5.61 times better than that of the TB. Monteiro et al. [3] developed an optic-fiber sensor for vibration composed of two FBGs attached to a cantilever structure. The response of the sensor to vibration was tested using two different vibration axes for frequencies between 10 and $500 \mathrm{~Hz}$. The results indicated that the cantilever structure was 
compatible with the power transformer mineral oil. For high temperatures, a permanent structural deformation was observed.

\subsection{Sound Assessment}

In the last decades, environmental requirements have gained strength in the society. In power transformers, the audible sound generated and emitted in the surrounding also raised environmental concerns. As power transformers (and reactors) are usually the most important sources of noise in a substation, it is necessary to consider their acoustic characteristics with great care, specifically for new purchases [47].

To detect applied sound signals in the transformer oil, Jongkil [48] designed a hybrid fiber optic sensor that is a combination of the Sagnac interferometer and an FBG. The applied sound frequency range was $5 \mathrm{kHz}$ to $90 \mathrm{kHz}$. The results showed that the fiber optic sensors using the Sagnac interferometer in the transformer oil could detect the applied sound frequency. Below a $50 \mathrm{kHz}$ applied sound frequency the sensitivity was higher, and thus lower above it.

\section{Fiber Optic Sensor for Thermal Parameter Assessment}

\section{Temperature}

The operating temperature of a transformer has a major influence on the ageing of its insulation and lifetime. The dielectric properties of transformer oil and its refractive index are affected by temperature [49]. Consequently, the variation in the refractive index of transformer oil is correlated to its temperature [50]. The life of a transformer is shortened considerably if it is operated consistently at elevated temperatures [51]. The most important temperature point to know is the winding hottest-spot temperature [52]. Transformer manufacturers must supply two minimum temperature indications, one for the top oil temperature and the other for the hottest winding temperature. A winding temperature indicator (WTI) is used to monitor temperature and alarm and trip protection circuits to protect the transformer. This method uses a thermal image of the transformer and is based on the transformer load current; calibration consists of assigning an assumed hot-spot temperature to a full-load current. However, it is not a direct measurement of the winding temperature and cannot reliably represent the transient conditions [51].

The transformer's hotspot temperature rise at rated power-which is one of the key dynamic thermal model (DTM) parameters-and can conventionally be determined by indirect measurements of average oil and winding temperature rise values during factory temperature rise tests, followed by the calculation of the hot-spot temperature rise on the basis of a pre-agreed steady-state thermal model $[53,54]$.

Nowadays, optical probes are widely used for temperature measurement. They have fast response times and are very accurate. During the last two decades, fiber optic temperature sensor technologies for direct hotspot temperature measurements have matured and become generally accepted by transformer users and manufacturers [55]. The use of fiber optic sensors allows utilities to meet multiple goals [56,57].

Integrating fiber optic temperature sensors to a transformer equipped with an online monitoring system would enable direct monitoring of the hotspot temperature during in-service operation. Gradnik et al. [54] used 10 fiber optic temperature sensors to monitor the operation of the winding temperature indicator (WTI) in a $400 \mathrm{kV}, 300$ MVA power transformer. These sensors were installed between the top winding conductors and in the oil cooling ducts inside the HV and LV windings.

Fiber Bragg grating (FBG) is a well-established and mature technology to solve the problem of temperature measurement within transformer windings. Jia et al. [58] designed a fiber grating temperature sensor by using an optical FBG demodulation module for temperature monitoring of transformer windings. Fourteen (14) optical fiber sensors (Single Mode Fiber) were installed on the high-voltage and low-voltage windings in a single-phase, 154-kV, 15/20-MVA power transformer filled 
with natural ester to measure the hotspot temperatures [59]. The hotspot temperature of the low voltage winding was $21.0^{\circ} \mathrm{C}$ higher than that calculated from the conventional heat run test, which was $108.4^{\circ} \mathrm{C}$.

Nasirul et al. [60] have proposed a fiber optic transformer winding temperature sensor based on the High Birefringence Fiber Loop Mirror (Hi-BiFLM) for online temperature monitoring in power transformers. This sensor works on the principle of interference between two counters propagating light waves having a phase difference. This sensor probe has demonstrated a high sensitivity of $0.58 \mathrm{~nm} /{ }^{\circ} \mathrm{C}$ and the minimum detectable temperature variation was $0.173{ }^{\circ} \mathrm{C}$.

Recently, a system for temperature measurement based on the fiber Bragg grating (FBG) sensor was designed for testing the 31.5-MVA/110-kV ONAN transformer [61]. The FBG sensing system was placed inside the transformer to monitor the temperature rise of the windings and iron core.

Distributed temperature sensors (DTS) are also widely used for temperature measurement. The main measuring principles are based on detecting the backscattering of light, e.g., using the Rayleigh, Raman, and Brillouin principles [20,62]:

- Rayleigh scattering is caused by the inhomogeneity of the fiber core and the backscattered Rayleigh light has the same wavelength as the input light. Brillouin scattering is caused by an acoustic wave from lattice vibration resulting from the interaction between the input light and the phonon.

- Brillouin backscattering is usually about 15 and $20 \mathrm{~dB}$ weaker than Rayleigh backscattering and has a frequency shift $\sim 11 \mathrm{GHz}$ for an SMF around $1550 \mathrm{~nm}$. This frequency shift is sensitive to temperature and strain.

- Raman scattering is caused by the phonons and is about $10 \mathrm{~dB}$ weaker than the spontaneous Brillouin scattering. A frequency shift $\sim 13.0 \mathrm{THz}$ with a wide bandwidth of $\sim 6 \mathrm{THz}$ is much larger than that of the Brillouin scattering. The intensity of the Stokes signal is temperature insensitive, whereas the anti-Stokes signal is temperature sensitive. Therefore, Raman scattering light can be used for temperature measurement.

Recently, Liu et al. [63] developed a new distributed optical fiber sensing technology to measure the transformer winding temperature, based on Raman scattering. The temperature measurement system using this new distributed optical fiber is shown in Figure 7.

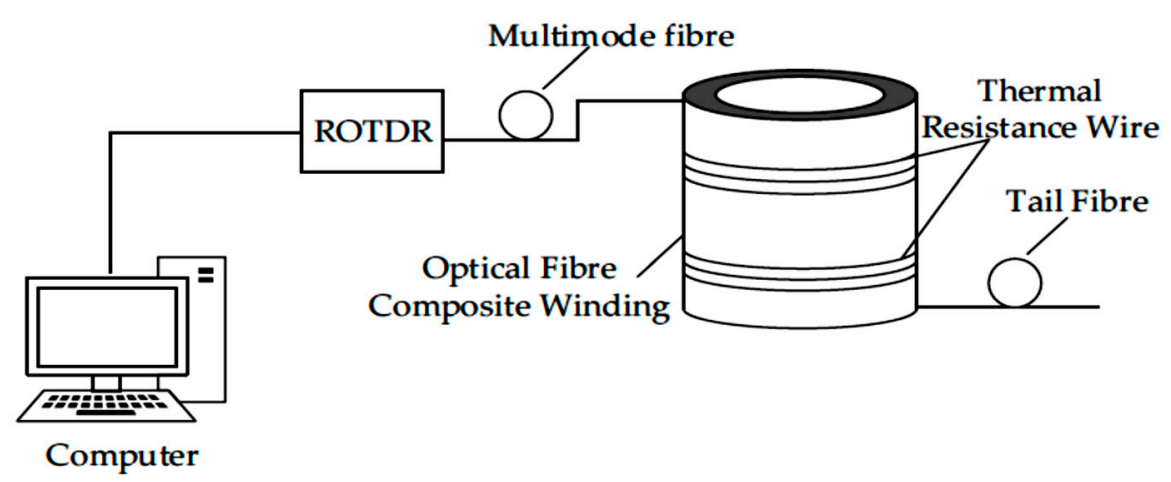

Figure 7. Temperature measurement system using optical fiber [63].

This distributed optical fiber can measure the winding temperature with an error limited to $1{ }^{\circ} \mathrm{C}$ and locate abnormal local temperature rise therein.

Marcel Nicola et al. [64] reported on a monitoring system composed of fiber optic sensors and a Kalman filter for monitoring the hotspot temperature of transformer windings. The complete system was integrated into a SCADA (Supervisory Control and Data Acquisition) system. This fiber optic technology is based on the dependence between temperature and the GaAs crystal property of light absorption. 
An FBG-based quasi-distributed thermal sensing system was realized and successfully applied in $35 \mathrm{kV} / 4000 \mathrm{kVA}$ oil immersed power transformers to monitor hotspot temperature [65]. The FBG was placed inside a transformer.

\section{Fiber Optic Sensor for Chemical Parameters Assessment}

\subsection{Dissolved Gas Analysis}

Dissolved gas analysis (DGA) is a powerful and the main diagnostic technique used to analyze dissolved gasses that are generated during the dielectric fluid and solid insulation decomposition process. Because the concentrations of certain gases and ratios between them are valuable information to diagnose electrical or thermal defects inside a transformer, detection of such gases dissolved in transformer oils is an effective method to detect incipient failures inside oil immersed power transformers. DGA has become a routine procedure. Still today, DGA is performed mostly by laboratories using standardized methods for the extraction and analysis of gases dissolved in oil. However, it is an expensive method involving oil sampling, shipping, and laboratory analysis, and it often takes days for the measurement results to be obtained. The main methods used to identify faults (above typical values) or stresses (below typical values) in transformers and accessories filled with mineral oils are the Duval Triangles and Pentagons, IEC Ratios, Rogers, Dornenburg, and Key Gas methods, together with dozens of other, lesser-used published methods, using for instance neural networks. They all primarily use hydrogen, methane, ethylene, ethane, and acetylene for fault identification. Although DGA can be installed on site and access the transformer oil with a connection port, they can only be installed outside of the transformers and the cost is still high. In the past decade, an increasing number of new monitors have emerged on the market, particularly hydrogen monitors using solid-state technology. This also includes various online gas monitors, allowing following the formation of some or all (from 2 to 11) of the other DGA gases and providing online diagnosis depending on manufacturers and models [66,67].

The main manufacturers use predominantly gas chromatography (GC), photoacoustic spectroscopy (PAS), solid-state (IC), thermal conductivity detector (TCD), non-dispersive infrared (NDIR), infrared (IR), near infrared (NIR), Fourier transform infrared (FTIR), fuel cell (FC), micro-electronic sensor, or electrochemical cells to detect and quantify fault gases from transformer oils [68]. These instruments are capable of detecting small changes in the analyzed concentration through the absorption of intensity-modulated laser light.

Recently, new methods have emerged to diagnose DGA, such as

- $\quad$ gene expression programming (GEP) [69];

- chemical reaction optimization (CRO) and twin support vector machine (TWSVM) [70];

- hypersphere multiclass support vector machine (HMSVM) and Dempster-Shafer (D-S) evidence theory (DET) [71]; and

- $\quad$ the modified grey wolf optimizer and least squares support vector machine (MGWO-LSSVM) with grey relational analysis (GRA) and empirical mode decomposition (EMD) [72].

According $[73,74]$, the gases that best detect an incipient fault are hydrogen and carbon monoxide. The $\mathrm{H}_{2}$ concentration detection range should be from 100 to $1000 \mathrm{ppm}$.

In transformers, the main types of fiber optic sensors, such as FBG, modified FBG, reflection, and interferometer, are used for monitoring $\mathrm{H}_{2}$ [20]. The detection range is 50 to $2000 \mathrm{ppm}$ with a 30 to $110{ }^{\circ} \mathrm{C}$ temperature range [75].

Currently, the hydrogen FBG technology is manufactured by coatings with a palladium (Pd) film and Pd alloys films, such as $\mathrm{Pd}-\mathrm{Cr}, \mathrm{Pd}-\mathrm{Au}, \mathrm{Pd}-\mathrm{Ni}, \mathrm{Pd}-\mathrm{Ag}$, and $\mathrm{Pd}-\mathrm{Ti}$ [20,76]. Hydrogen sensors based on pure $\mathrm{Pd}$ film are affected by the fatal fracture of $\mathrm{Pd}$ film caused by its $\alpha-\beta$ phase transition [77]. By alloying Pd with other metals, however, it is possible to improve the structural stability of the hydrogen-sensitive films [77]. 
A thin palladium film deposited on a glass plate for the detection of $\mathrm{H}_{2}$ dissolved in transformer oil was developed by Bodzenta et al. [78]. The sensor had a high sensitivity for 200-1500 ppm $\mathrm{H}_{2}$ dissolved in the oil at $20-120^{\circ} \mathrm{C}$. For low $\mathrm{H}_{2}$ concentrations, this sensor exhibited good sensitivity and stability up to $90{ }^{\circ} \mathrm{C}$. To detect $\mathrm{H}_{2}$ dissolved in transformer oil, Butler et al. [79] developed a $\mathrm{Pd}-\mathrm{Ag}$-based micro-optical fiber sensor. The sensitivity of the sensor was $100 \mathrm{ppm}$ for temperatures ranging from 20 to $120^{\circ} \mathrm{C}$.

In [80], two different optical fiber sensors based on FBG were produced and attached to a modified $\mathrm{Pd}$ foil. These sensors were tested in transformer mineral oil at $90^{\circ} \mathrm{C}$ for the measurement of dissolved hydrogen concentrations in the range of 20 to $3200 \mathrm{ppm}$. More recently, the same authors created fifteen FGBs coated with palladium $(\mathrm{Pd})$ for monitoring hydrogen $\left(\mathrm{H}_{2}\right)$ in power transformers. These sensors were evaluated at $90^{\circ} \mathrm{C}$ and were able to dissolve $\mathrm{H}_{2}$ concentrations ranging from 5 to $2700 \mathrm{ppm}$ [81].

Mak et al. [75] showed that a PTFE-Pd-capped Mg-Ti thin film-based fiber optic sensor was able to dissolve the $\mathrm{H}_{2}$ concentration in transformer oil between 5 and $15 \mathrm{ppm}$ at $21^{\circ} \mathrm{C}, 5$ and $30 \mathrm{ppm}$ at $40^{\circ} \mathrm{C}, 5$ and $130 \mathrm{ppm}$ at $60^{\circ} \mathrm{C}$, and 5 and $1500 \mathrm{ppm}$ at $80^{\circ} \mathrm{C}$.

Samsudin et al. [82] compared two FBG sensors based on different palladium (Pd) coating ratios (100\% palladium $\left(\mathrm{Pd}_{100}\right)$ and a mixture of palladium:chromium $\left(\mathrm{Pd}_{58} \mathrm{Cr}_{42}\right)$ of 58:42): $\mathrm{The} \mathrm{Pd}_{100}$ sensor showed a higher sensitivity than the $\mathrm{Pd}_{58} \mathrm{Cr}_{42}$; the response range was limited to lower hydrogen content.

Another fiber optic sensor based on a $\mathrm{WO}_{3}-\mathrm{Pd}_{2} \mathrm{Pt}-\mathrm{Pt}$ composite film and a self-referenced demodulation method was used to monitor the hydrogen. Two Bragg gratings associated with high-low reflectivity, using a $\mathrm{WO}_{3}-\mathrm{Pd}_{2} \mathrm{Pt}-\mathrm{Pt}$ composite film, were used to detect the $\mathrm{H}_{2}$ concentration of $20 \mathrm{ppm}$ at $25^{\circ} \mathrm{C}$ [83]. The hydrogen sensor showed a quick response rate, good repeatability, as well as anti-humidity interference and selectivity during the hydrogen response. This sensor showed a better anti-humidity interference capacity than the $\mathrm{H}_{2}$ sensor based on a Pd/Au film.

A highly sensitive and temperature-robust photonic crystal fiber (PCF) modal interferometer coated with $\mathrm{Pd} / \mathrm{WO}_{3}$ film was developed and studied as to real-time monitoring of dissolved $\mathrm{H}_{2}$ concentrations in transformer oil [84]. This sensor reached $0.109 \mathrm{pm} /(\mu \mathrm{L} / \mathrm{l})$ in the oil, with a measurement ranging from 0 to $10,000 \mu \mathrm{L} / 1$ with a response time of less than $33 \mathrm{~min}$.

Acetylene $\left(\mathrm{C}_{2} \mathrm{H}_{2}\right)$ is another very important gas in DGA, the presence of acetylene indicating arcing or severe overheating inside the transformer. In 2009, EPRI [85] developed a new sensor for dissolved acetylene detection by direct oil transmission measurement. The short-term detection accuracy of the oil transmission measurement method was $25 \mathrm{ppm}$, and the detection resolution was around 10 ppm. In 2011, Yang et al. [86] designed a fiber optic acetylene gas sensor based on a micro-structured optical fiber Bragg grating (MOFBG). The MOFBG for the gas detection was based on absorption spectroscopy. This sensor showed a response to $\mathrm{C}_{2} \mathrm{H}_{2}$ in the range of $1.5 \%-7 \%$, which is not sufficiently low to be used as a detection limit in transformer oil monitoring applications [76].

Methane $\left(\mathrm{CH}_{4}\right)$ with hydrogen is produced in large quantities if the internal temperature of the power transformer rises up to a range of 150 to $30{ }^{\circ} \mathrm{C}$ due to abnormal thermal stresses. In 2011, an optical fiber sensing element based on luminescence quenching of cryptophane-A/silica nanowires was successfully made and used to dynamically monitor methane gas at low concentrations, i.e., below $3.5 \%(\mathrm{v} / \mathrm{v})$ [87]. The response of the fiber optic showed within a methane concentration ranges between $0.1 \%$ and $3.5 \%(\mathrm{v} / \mathrm{v})$ with a detection limit below $0.1 \%(\mathrm{v} / \mathrm{v})$.

Mishra et al. [88] fabricated and characterized a fiber optic sensor based on surface plasmon resonance technology using graphene-carbon nanotubes/poly(methyl methacrylate) (GCNT/PMMA) hybrid composites for the detection of methane. This sensor showed a total shift in resonance wavelength for a methane gas concentration range of 10-100 ppm. Since a methane concentration below 100 ppm is considered normal, while concentrations above $1000 \mathrm{ppm}$ reveal overheated oil or partial discharges, this sensor can be used in transformer.

An optical fiber sensor coated with a thin silicone cladding of cryptophane A into a fused-silica capillary for methane $\left(\mathrm{CH}_{4}\right)$ gas determination at ambient conditions was developed [89]. Its response 
to $\mathrm{CH}_{4}$ was determined by the light filtered through the fiber. Its dynamic concentration range for $\mathrm{CH}_{4}$ was $0.0 \%-16.0 \%(\mathrm{v} / \mathrm{v})$ with a detection limit of $0.15 \%(\mathrm{v} / \mathrm{v})$.

\subsection{Moisture Assessment}

Moisture is one of the worst enemies of a power transformer and one of the most common causes of deterioration of the insulating quality of the fluid. Water can be present in dielectric fluid in three states [90]:

- In a dissolved form.

- As "bound" water, where water molecules attach themselves to fibrous particles (including dust and dirt), as well as acids formed during the oxidation process of the fluid. Once it is "bound" to another molecule aside from the fluid itself, it never moves, until filtration takes place.

- As free water normally found at the bottom of the container holding the insulating fluid.

The determination of water content is one of the most frequently used methods around the world. The methods can be found in [91]. The conventional method to evaluate the moisture is the Karl Fischer measurement. Several factors may affect the results of Karl Fischer analyses, such as the penetration of moisture from the atmosphere during sampling, transport and preparation of samples, and different aging by-products that reacts with iodine [91].

In the last decade, capacitive sensors have been increasingly used to evaluate moisture in power transformers. This mostly uses capacitive thin film polymer sensors [92]. Experience has shown that effective integration of moisture sensors into on-line diagnostic systems requires appropriate positioning of the sensor in order to obtain a correct moisture profile [92]. This method measures the water vapor pressure in the gas phase and calculates the moisture level in the solid insulation (provided an equilibrium is established). Actually, a fiber optic sensor has been developed and used for the measurement of moisture in power transformers.

Rodriguez-Rodriguez et al. [93] developed an optical fiber sensor based on evanescent-wave scattering to detect moisture in an electrical apparatus. This optical fiber moisture sensor was prepared by coating a 1-mm polymer optical fiber with a 30-micron-thick film of polyvinyl acetate PVA. The sensor has been demonstrated in dry, semi dry, and water-saturated conditions. Laskar et al. [94] have proposed an optical fiber sensor and temperature sensor-based instrumentation system to measure the moisture content in transformer oil. The moisture content of the transformer oil sample was determined by a micro-controller-based system with trained ANN algorithms that realizes the readings of the bare bent multimode optical fiber sensor and the temperature sensor. Zhang et al. [95] developed a poly(methyl methacrylate) (PMMA)-based optical fiber Bragg grating (POFBG) to monitor moisture in transformer oil. Sensitivity of the POFBG wavelength change to moisture content of $29 \mathrm{pm} / \mathrm{ppm}$ was demonstrated, indicating detectable water content better than $0.05 \mathrm{ppm}$. Kung et al. [96] developed a fiber optic sensor using the $\pi$-phase shifted grating (PS-FBG) technology for simultaneously monitoring moisture and temperature. The sensor consisted of a pair of PS-FBGs where one had a standard polyimide coating and the other was coated with many layers of the same high temperature-resistant material.

A D-shaped optical fiber sensor coated with a thick platinum thin layer was designed to detect the response of transverse electric field (TE) power towards the content of moisture in the transformer oil [97]. The changes in TE power showed that the sensor was fast and had good sensitivity. In a recent paper published by Akre et al. [98], the authors developed a new fiber optic sensor based on FBG technology to monitor moisture, vibration, and temperature inside oil-filled transformers. The designed sensor can measure wideband vibration signal from $2 \mathrm{~Hz}$ to $2 \mathrm{kHz}$. This thin fiber optic sensor was calibrated for moisture ppm measurement of ester and mineral oil. The advantages of this sensor include simultaneous measurement of vibration and fast temperature changes. This new sensor can also measure moisture content, which, combined with temperature measurements, can be correlated to moisture change in oil. 


\subsection{Furfural Assessment}

Oil/paper insulation deteriorates gradually during a long-lasting process, thus reducing its insulation level. During this process, oil/paper insulation material breaks down and produces furan, alcohols, acids, esters and ketones, reflecting its insulation properties, which dissolve in oil [99]. Six furanic compounds, namely 2-furoic acid, 2-acetylfuran (2-ACF), 2-furfural (2-FAL), 2-furfurylalcohol (2-FOL), 5-methyl-2-furfural (5-MEF), and 5-hydroxymethyl-2-furfural (5-HMF), were identified as potential paper ageing indicators. Of these furanic compounds, 2-FAL is used more than the others due to its greater stability and its availability at higher concentrations than the others in oil $[2,100]$.

Nowadays, the usual methods for detecting furfural content in oil are high-level liquid chromatography, ultraviolet spectrophotometry, and colorimetry [101]. These methods have been used for several decades and are very useful in transformer monitoring, but they present some limits. Liquid chromatography is highly accurate and repeatable. However, it presents problems like elution difficulties and the "extra column effect". Although, ultraviolet spectrophotometry is quick, it may be affected by other organic matters in oil and has poor stability. The colorimetric approach is inexpensive, but the reagent used is a strong carcinogen, and the experimental errors are large. Generally, the limitations of the various approaches for detecting dissolved micro features in oil are their complexity; also, most of the equipment needs to be used in the laboratory and oil detection cannot be done in situ.

In 2007, Jalbert et al. [102] suggested to use methanol and ethanol in transformer oil as paper ageing indicators. The main advantage of methanol over conventional ageing indicators is its ability to indicate the early stage of paper ageing [102]. A standard method for measuring methanol and ethanol in transformer oil is under development. The crystalline index behavior of aged insulating paper and its correlation with paper degradation was investigated in [103]. Li et al. [104] proposed a novel method to monitor of insulation paper degradation/aging, based on the dispersion of staining colors (DSCs) of cellulose fibers in oil. Recently, it was suggested to detect the presence of furfural in oil using surface-enhanced Raman spectroscopy [99], which is based on the Raman effect, allowing to find the structure, properties, and content of material through scattering light produced by laser irradiation. During the same year, in [105] a novel no-extraction furfural detection method based on UV-Vis spectrometry was proposed to evaluate the aging of paper insulation by the degree of polymerization (DP). This novel spectroscopy approach used the colorimetric reaction with aniline to measure furfural in transformer oil.

The use of optical fibers to detect the furfural is practically nonexistent in the literature. An optical device based on a surface plasmon resonance (SPR) excitation in a plastic optical fiber (POF) and molecularly imprinted polymers (MIP) platform was proposed for the measurement of very low levels $(<0.15 \mathrm{ppm})$ of furfural (2-FAL) in transformer oils [106]. In-service oil samples from two $145 \mathrm{kV}$ oil insulated current transformers were considered to verify the response of the POF-MIP sensor in used oil. This sensor was used to determine 2-FAL in oil inside the transformer, due to the very small oil volume required for the determination. Direct measurement was also done by placing the sensor directly inside the flowing circuit.

A multichannel optical chemical sensor based on molecularly imprinted polymers (MIPs) and surface plasmon resonance (SPR) in a D-shaped plastic optical fiber (POF) was proposed for simultaneous determination of dibenzyl disulfide (DBDS) and furfural directly in transformer oil [107]. The limit of detection was extended to only about $1 \mathrm{ppm}$ for the two analytes. Recently, these same authors [108] again used the SPR-POF-MIP sensor for 2-FAL detection in power transformer insulating oil, with a limit of detection of about $4 \mu \mathrm{M}$. 


\subsection{Oil Level Detection}

In oil-filled transformers, an oil-level gauge is required so that the correct oil level can be maintained. A very low oil level can expose energized and current-carrying components (that are designed to operate in oil) to overheating or electrical flashover [109]. Oil expansion followed by over pressurization would occur if the oil level is too high. Thus, early monitoring of the oil level is very important. In [110], the authors developed a system using optical fiber grating sensors for oil level detection devices for the treatment and control of the Digital Signal Processor (DSP) core. The transformer insulating oil has been accurately measured in real time. Experimental results have shown that the system had high precision measurement, as well as good stability and reliability. Deba et al. [111] presented two different optical fiber-based sensor systems for measurement of the oil level in a power transformer. A multimode fiber was used to make the sensors. The principle of measurement was based on the change of light intensity at the output due to the change in the refractive index of the cladding medium (transformer oil). The sensing range of these two sensors can be multiplexed as per user requirement. The fiber optic sensor (cladding-removed portion) was kept immersed in the transformer oil to monitor the oil level.

\subsection{Oil Ageing Assessment}

In service conditions the quality of the insulating fluids gradually deteriorates under the impact of electrical, thermal, and chemical stresses. The insulating oil in a transformer becomes increasingly contaminated as the transformer ages in service. Contaminants include particulate debris from thermal, oxidative, or electrical degradation byproducts (sludge, acids, $x$-wax, etc.) of oil or solid insulation, fibers, gases, moisture, etc.

Kim et al. [112] constructed an all-optical fiber-sensing system by employing Mach-Zehnder interferometry for monitoring and evaluating the condition of transformer oil. These authors have demonstrated that this fiber optic sensor could respond suitably to the acoustic waves propagating in the transformer oil. It was observed that the sound attenuation measured using the fiber optic sensor increases as the aging process of transformer oil proceeds. Rao et al. [113] modelled an optical fiber sensor based on evanescent field of absorption for estimating sludge in transformer oil.

In order to study the influence of aging fiber sheaths on transformer oil, Liu et al. [114] used two types of special optical fibers, one with thermoplastic polyester elastomer (TPEE) and the other poly tetra fluoroethylene (PTFE), as sheaths were subjected to thermally accelerated aging in transformer oil at $130^{\circ} \mathrm{C}$. Compared with TPEE on different parameters, such as DDF, DP, acidity, water content, breakdown voltage, and volume resistivity, PTFE showed good behavior on oil ageing. Therefore, it was suggested to use a fiber with a jacket material of PTFE built into the transformer. So, when the fiber is laid in the transformer, the content of the micro water and acid value must be monitored in the control oil.

\section{Performance Comparison of Fiber Optic-Based Sensors}

Various approaches have been proposed so far, as reviewed in this manuscript, each of them having their own advantages. To list and compare these approaches, Table 2 summarizes the performance of the fiber optic-based sensors used for power transformer condition assessment. 
Table 2. Performance comparison of the fiber optic-based sensors used in power transformers.

\begin{tabular}{|c|c|c|c|c|c|}
\hline & \multirow{2}{*}{$\begin{array}{l}\text { Monitored } \\
\text { Parameters }\end{array}$} & \multirow{2}{*}{ Fiber Optic Sensors } & \multicolumn{2}{|c|}{ Performance Comparison } & \multirow{2}{*}{ References } \\
\hline & & & Advantages & Disadvantages & \\
\hline \multirow{6}{*}{$\begin{array}{l}\text { Electrical } \\
\text { parameters }\end{array}$} & \multirow[t]{2}{*}{$\begin{array}{c}\text { Partial } \\
\text { discharges }\end{array}$} & $\begin{array}{l}\text { Fiber Bragg grating } \\
\text { (FBG) }\end{array}$ & $\begin{array}{l}\text { Small size, stronger } \\
\text { multiplexing } \\
\text { capability }\end{array}$ & Low sensitivity & [20] \\
\hline & & $\begin{array}{c}\text { Interferometers } \\
\text { (Michelson, } \\
\text { Fabry-Perot, Sagnac, } \\
\text { Mach-Zehnder) }\end{array}$ & $\begin{array}{l}\text { High sensitivity, } \\
\text { large flat response }\end{array}$ & Difficult to multiplex & {$[19,20,23,24]$} \\
\hline & $\begin{array}{l}\text { Breakdown } \\
\text { voltage }\end{array}$ & Multimode fiber & - & - & {$[29,30]$} \\
\hline & \multirow[t]{2}{*}{ Current } & All-fiber optic & $\begin{array}{c}\text { Any number of } \\
\text { turns } \\
\text { No size limits } \\
\text { Interferometric } \\
\text { design; } \\
\text { Easy to implement } \\
\text { and to increase the } \\
\text { sensitivity }\end{array}$ & $\begin{array}{l}\text { More vulnerable to } \\
\text { pressure, } \\
\text { temperature } \\
\text { gradients, } \\
\text { mechanical } \\
\text { vibrations and other } \\
\text { environmental noises }\end{array}$ & [33] \\
\hline & & Polarimetric with IOPS & $\begin{array}{c}\text { Standard } \\
\text { single-mode fiber }\end{array}$ & $\begin{array}{l}\text { Does not reach the } \\
\text { accuracy of } \\
\text { interferometric } \\
\text { sensors for DCs }\end{array}$ & [39] \\
\hline & Voltage & BGO crystals & $\begin{array}{l}\text { Excellent linearity; } \\
\text { stable behavior at } \\
\text { least one hour, even } \\
\text { under DC operation }\end{array}$ & $\begin{array}{l}\text { High sensitivity of } \\
\text { the EO crystal }\end{array}$ & {$[34,35]$} \\
\hline \multirow{2}{*}{$\begin{array}{l}\text { Mechanical } \\
\text { parameters }\end{array}$} & \multirow{2}{*}{$\begin{array}{l}\text { Winding } \\
\text { deformation } \\
\text { and vibration } \\
\text { Sound } \\
\text { (detection } \\
\text { range: } 5 \\
\text { kHz } \sim 90 \mathrm{kHz} \text { ) }\end{array}$} & $\begin{array}{l}\text { Fabry-Perot } \\
\text { interferometer } \\
\text { FBG }\end{array}$ & $\begin{array}{c}\text { High sensitivity (20 } \\
\text { Hz to } 1000 \mathrm{~Hz}) \\
\text { High sensitivity }\end{array}$ & - & $\begin{array}{l}{[45]} \\
{[43]}\end{array}$ \\
\hline & & $\begin{array}{c}\text { Combined Sagnac and } \\
\text { FBG }\end{array}$ & $\begin{array}{l}\text { High sensitivity } \\
\text { below } 50 \mathrm{kHz}\end{array}$ & $\begin{array}{l}\text { Low sensitivity } \\
\text { above } 50 \mathrm{kHz}\end{array}$ & [48] \\
\hline \multirow{4}{*}{$\begin{array}{l}\text { Thermal } \\
\text { parameters }\end{array}$} & \multirow{4}{*}{ Temperature } & FBG & High sensitivity & $\begin{array}{l}\text { Quasi-distributed } \\
\text { thermal sensing }\end{array}$ & {$[20,58]$} \\
\hline & & FBG quasi-distributed & High sensitivity & $\begin{array}{l}\text { Quasi-distributed } \\
\text { thermal sensing }\end{array}$ & [65] \\
\hline & & Hi-BiFLM & High sensitivity & - & {$[60]$} \\
\hline & & ROTDR & Distributed sensing & $\begin{array}{l}\text { Low spatial } \\
\text { resolution }\end{array}$ & {$[20,63]$} \\
\hline \multirow{6}{*}{$\begin{array}{l}\text { Chemical } \\
\text { parameters }\end{array}$} & \multirow{6}{*}{ Hydrogen } & FBG with Pd film & $\begin{array}{l}\text { Thickness and } \\
\text { material film } \\
\text { improve sensitivity; } \\
\text { High sensitivity for } \\
200-1500 \text { ppm at } \\
20-120^{\circ} \mathrm{C}\end{array}$ & $\begin{array}{c}\text { Pd or Pd-based } \\
\text { composite are } \\
\text { required to absorb } \\
\mathrm{H}_{2}\end{array}$ & {$[20,78]$} \\
\hline & & $\begin{array}{l}\text { FBG with } \mathrm{Pd}-\mathrm{Ag}, \\
\text { Pd-Cr, } \mathrm{Pd}-\mathrm{Au}, \mathrm{Pd}-\mathrm{Ni}, \\
\text { Pd-Ti films }\end{array}$ & $\begin{array}{l}\text { Thickness and } \\
\text { material film } \\
\text { improve sensitivity; }\end{array}$ & $\begin{array}{l}\text { Pd or Pd-based } \\
\text { composite are } \\
\text { required to absorb } \\
\mathrm{H}_{2}\end{array}$ & {$[20,76,79]$} \\
\hline & & Two FBGs with Pd film & $\begin{array}{l}\text { High sensitivity for } 5 \\
\text { to } 2700 \text { ppm at } 90^{\circ} \mathrm{C}\end{array}$ & - & {$[80,81]$} \\
\hline & & $\begin{array}{c}\text { POF-PTFE-Pd-capped } \\
\text { Mg-Ti }\end{array}$ & $\begin{array}{l}\text { High sensitivity for } \\
5-1500 \mathrm{ppm} \text { at } 80^{\circ} \mathrm{C}\end{array}$ & 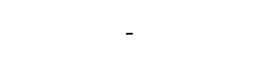 & [75] \\
\hline & & $\begin{array}{l}\text { FBG with } \mathrm{Pd}_{58} \mathrm{Cr}_{42} \\
\text { film }\end{array}$ & 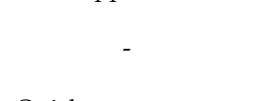 & $\begin{array}{l}\text { Limited to lower } \\
\text { hydrogen content, } \\
\mathrm{Pd}>\mathrm{Pd}_{58} \mathrm{Cr}_{42}\end{array}$ & [82] \\
\hline & & $\begin{array}{c}\text { FBG with } \\
\mathrm{WO}_{3}-\mathrm{Pd}_{2} \mathrm{Pt}-\mathrm{Pt} \text { film }\end{array}$ & $\begin{array}{l}\text { Quick response rate, } \\
\text { good repeatability, } \\
\text { anti-humidity } \\
\text { interference and } \\
\text { selectivity } \\
\text { High sensitivity, } \\
\text { Temperature-robust }\end{array}$ & Only $20 \mathrm{ppm}$ at $25^{\circ} \mathrm{C}$ & {$[20,84]$} \\
\hline
\end{tabular}


Table 2. Cont.

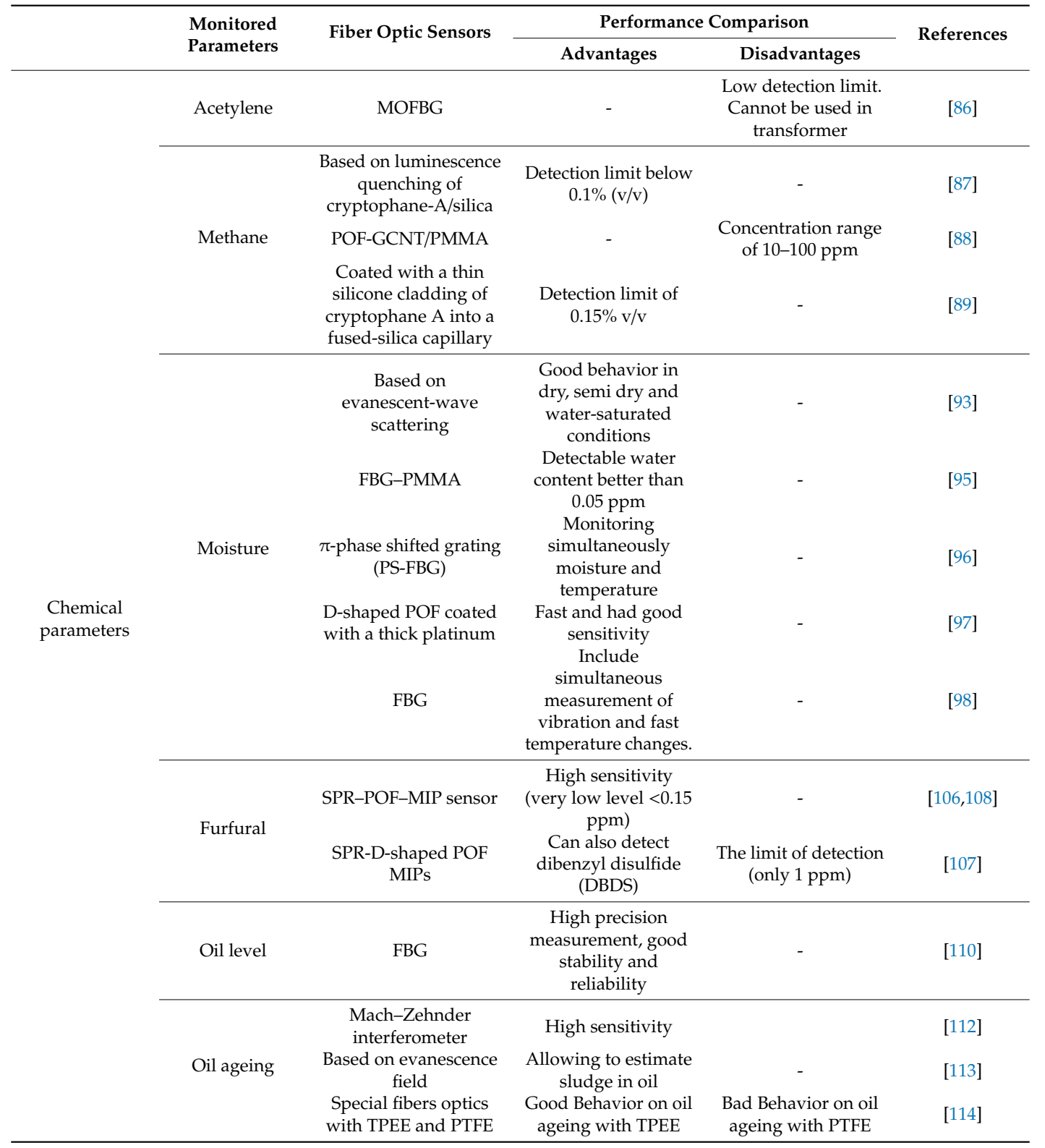

\section{Some Applications in Other Power Equipment}

Optical fibers find applications not only in power transformers and related hardware but also in other components of the power grid including insulators, cables, generators, etc. Optical fiber-based sensors are deployed to monitor a variety of parameters, including leakage current, electric fields, vibration, loads, etc. Few examples are listed hereafter. An Equivalent Salt Deposit Density (ESDD) optical FBG sensor for transmission lines was designed for assessing the accumulated contamination on the insulator. The sensibility of the sensors indicated an accuracy less than $10 \%$ [115]. The optical fiber sensor based on Brillouin optical time domain reflectometry (BOTDR) was used to monitor online temperature on power transmission lines [116]. The temperature difference between the conductor and the fiber was $0.018^{\circ} \mathrm{C}$. Cirigliano et al. [117] proposed a distributed temperature sensor based on the Raman principle to monitor temperature distribution over optical ground wires and phase conductors. The fiber optic sensor showed good agreement with a realistic environment. The FBG optical sensor is used to monitor deformation, vibration, and the safety tower foundation in power plants [20]. 


\section{Challenges and Future Directions}

Though fiber optical sensors have been developed rapidly and successfully applied in different equipment, including power transformers, there are still windows for improvement, such as the resolution and sensitivity of the optical fibers. The challenges and future directions mainly include:

(1) Verification of the long-term accuracy of the design.

(2) Research on the possibility for multiple functional fiber optic sensors. Since the parameters in health monitoring of power transformers are very large as defined in [1], optical fiber manufacturers cannot continue to design sensors for each specific parameter. The challenge therefore consists in designing multi-function fiber optic sensors that can monitor several parameters at the same time. For example, the authors in [118] used an optical fiber sensor and near infrared (NIR) based on the reflection mode to detect the formation of methane, ethylene, propane, and butane due to partial discharges in the transformer oil. Akre et al. [98] also proposed a sensor with the ability to simultaneously measure moisture, vibration, and temperature.

(3) There is a lack of relevant standards and guides for fiber optic sensors, especially for testing techniques. Such normative references need to be developed.

\section{Conclusions}

A review of the fiber optic sensors in power transformers was presented in this paper. The application of monitoring fiber optic sensors to transformers offers benefits, particularly in detecting faults that can be fixed before causing irreparable damage. Many fiber optic sensors have been demonstrated to access parameters useful for monitoring power transformers. These fiber sensors are differentiated according to the method whereby optical radiation is modulated by the parameter of interest (e.g., intensity, phase, polarization, or wavelength). Even though many parameters are monitored in transformers by fiber optic-based sensors, there is still a dearth of information, which needs to be rectified. Optical sensors capable of integrating with technological advancement are of interest due to a consequent reduction in design costs, immunity to stray magnetic/electric fields and an improvement in technical portability. The challenge consists in developing multi-functional and low-cost optical fiber sensors that are economically viable, yet retain the critical advantages of the technology platform. Continuing efforts are necessary for optical fiber manufacturers to research and develop more performant optical fibers; this is what will assure the future of this domain.

Author Contributions: Both authors contributed equally to the reported research and writing of the paper. All authors have read and agreed to the published version of the manuscript.

Funding: This research was funded by Natural Science and Engineering Research Council (NSERC) Discovery grant number RPGPIN-2015-044 03.

Conflicts of Interest: The authors declare no conflict of interest.

\section{References}

1. Fofana, I.; Hadjadj, Y. Electrical-based diagnostic techniques for assessing insulation condition in aged transformers. Energies 2016, 9, 679. [CrossRef]

2. N'cho, J.S.; Fofana, I.; Hadjadj, Y.; Beroual, A. Review of physicochemical-based diagnostic techniques for assessing insulation condition in aged transformers. Energies 2016, 9, 367. [CrossRef]

3. Catarina, S.M.; Vaz, A.; Viveiros, D.; Linhares, C.; Tavares, S.M.O.; Mendes, H.; Silva, S.O.; Marques, P.V.S.; Frazão, O. FBG two-dimensional vibration sensor for power transformers. In Proceedings of the Seventh European Workshop on Optical Fiber Sensors, Limassol, Cyprus, 28 August 2019.

4. Lindgren, M.; Kharezy, M. Fiber Optic Sensors for High-Voltage Applications; SP Technical Research Institute of Sweden: Bros, Sweden, 2015.

5. Tenbohlen, S.; Stirl, T.; Bastos, G.; Baldauf, J.; Mayer, P.; Stach, M.; Breitenbauch, B.; Huber, R. Experience-based evaluation of economic benefits of on-line monitoring systems for power transformers. In Proceedings of the CIGRE Session, Paris, France, 25-30 August 2002. 
6. Gupta, B.D. Fiber Optic Sensors: Principles and Applications; New India Publishing: New Delhi, India, 2006.

7. Barrias, A.; Casas, J.R.; Villalba, S. A review of distributed optical fiber sensors for civil engineering applications. Sensors 2016, 16, 748. [CrossRef] [PubMed]

8. Meggitt, B.T. Fiber optics in sensor instrumentation. In Instrumentation Reference Book, 4th ed.; Boyes, W., Ed.; Butterworth-Heinemann/Elsevier: Oxford, UK, 2010; pp. 191-216.

9. Critchley, L. Assisting Gas Detection with Fiber Optics. AZoOptics. 10 November 2019. Available online: https://www.azooptics.com/Article.aspx?ArticleID=1505 (accessed on 14 January 2020).

10. Introduction to Fiber Optic Sensors and Their Types with Applications. Available online: https://www. elprocus.com/diffrent-types-of-fiber-optic-sensors/ (accessed on 14 January 2020).

11. Krohn, D.A.; Mac Douglas, T.; Mendez, A. Fiber Optic Sensors: Fundamentals and Applications, 4th ed.; SPIE Press: Bellinggham, DC, USA, 2014.

12. Mansoor, A.; Kanishka, T. Fiber Optic Sensors: Fundamentals, Principles and Applications, Nufern Technical Center. 2014. Available online: https://www.nufern.com/library/item/id/464/\# (accessed on 14 January 2020).

13. Udd, E.; Spillman, W.B. Fiber Optic Sensors: An Introduction for Engineers and Scientists, 2nd ed.; John Wiley \& Sons: Hoboken, NJ, USA, 2011.

14. Udd, E.; Shulz, W.L.; Seim, J.M.; Morrell, M.; Weaver, T.L.; Bush, J.; Adamovsky, G. Fiber optic distributed sensing systems for harsh aerospace environments. In Proceedings of the Society of Photo-Optical Instrumentation Engineers on the Smart Structures and Materials: Industrial and Commercial Applications of Smart Structures Technologies, Newport Beach, CA, USA, 9 July 1999.

15. Renshaw, J.; Van der Zel, L.; Guimaraes, M. Low-Cost, High-Resolution Fiber-Optic Sensors for Power Industry Applications; Technical report; EPRI: Palo Alto, CA, USA, November 2016; pp. 1-15.

16. Matias, I.R.; Ikezawa, S.; Corres, J. Fiber Optic Sensors: Current Status and future Possibilities, 1st ed.; In Smart Sensors, Measurement and Instrumentation; Springer International Publishing: Basel, Switzerland, 2017.

17. CIGRE Working Group D1.29. Partial Discharges in Transformers; CIGRE Report 676; CIGRE: London, UK, 2017.

18. Li, J.; Li, X.; Du, L.; Cao, M.; Qian, G. An intelligent sensor for the ultra-high-frequency partial discharge online monitoring of power transformers. Energies 2016, 9, 383. [CrossRef]

19. Wang, Y.; Li, X.; Gao, Y.; Zhang, H.; Wang, D.; Jin, B. Partial discharge ultrasound detection using the sagnac interferometer system. Sensors 2018, 18, 1425. [CrossRef]

20. Quan, C.; Yang, L.; Jing, R.; Jianzhong, Z.; Jun, Y.; Libo, Y.; Gang-Ding, P. Review on fiber-optic sensing in health monitoring of power grids. Opt. Eng. 2019, 58, 072007-1-072007-20.

21. Ghorat, M.; Gharehpetian, G.B.; Latifi, H.; Hejazi, M.A.; Bagheri, M. High-resolution FBG-based fiber-optic sensor with temperature compensation for PD monitoring. Sensors 2019, 19, 5285. [CrossRef]

22. American National Standard, IEEE Guide for the Detection and Location of Acoustic Emissions from Partial Discharges in Oil-Immersed Power Transformers and Reactors; In IEEE Power Engineering Society; IEEE Std. C57. 127-2007; Transformers Committee: New York, NY, USA, 2007; pp. 9-18.

23. Qi-Chao, C.; Wei-Chao, Z.; Hong, Z. Response bandwidth design of fabry-perot sensors for partial discharge detection based on frequency analysis. J. Sens. 2019, 2019, 11.

24. Zhou, H.; Ma, G.; Zhang, M.; Zhang, H.; Li, C. A high sensitivity optical fiber interferometer sensor for acoustic emission detection of partial discharge in power transformer. IEEE Sens. J. 2019. [CrossRef]

25. Ma, G.-M.; Zhou, H.-Y.; Shi, C.; Li, Y.-B.; Zhang, Q.; Li, C.-R.; Zheng, Q. Distributed partial discharge detection in a power transformer based on phase-shifted FBG. IEEE Sens. J. 2018, 18, 2788-2795.

26. Gao, C.; Yu, L.; Xu, Y.; Wang, W.; Wang, S.; Wang, P. Partial discharge localization inside transformer windings via fiber-optic acoustic sensor array. IEEE Trans. Power Deliv. 2018, 34, 1251-1260. [CrossRef]

27. Robinson, N.; Hons, B.S.C. Transformer Oil Analysis; Wearcheck Africa, Technical Bulletin. 2006. Available online: https://www.wearcheck.co.za/downloads/bulletins/bulletin/tech36.pdf (accessed on 25 January 2020).

28. Tang, C.; Liao, R.J.; Yang, L.J.; Huang, F.L. Research on the dielectric properties and breakdown voltage of transformer oil paper insulation after accelerating thermal ageing. In Proceedings of the International Conference on High Voltage Engineering and Application, New Orleans, LA, USA, 11-14 October 2010.

29. Mahanta, D.K.; Laskar, S. Investigation of transformer oil breakdown using optical fiber as sensor. IEEE Trans. Dielectr. Electr. Insul. 2018, 25, 316-320. [CrossRef]

30. Mahanta, D.K.; Laskar, S. Breakdown voltage based transformer oil analysis using optical fiber as sensor. In Proceedings of the 22nd Microoptics Conference (MOC), Tokyo, Japan, 19-22 November 2017. 
31. Laurensse, I.J.; Koreman, C.G.A.; Rutgers, W.R.; Van der Wey, A.H. Applications for optical current and voltage sensors. Sens. Actuators 1989, 17, 181-186. [CrossRef]

32. Distribution Sensors: Laboratory Development and Test Result. Available online: https://www.epri.com/\#/ pages/product/3002016393/?lang=en-US (accessed on 25 January 2020).

33. Silva, R.M.; Martins, H.; Nascimento, I.; Baptista, J.M.; Ribeiro, A.L.; Santos, J.L.; Jorge, P.; Frazão, O. Optical current sensors for high power systems: A review. Appl. Sci. 2012, 2, 602-628. [CrossRef]

34. Mike, R. Advantages of Optical Current and Voltage Sensors and Transformers; EE Publishers: Mudesteve, South Africa, 2017; Available online: https://www.ee.co.za/article/advantages-optical-current-voltage-sensorstransformers.html (accessed on 26 January 2020).

35. Klaus, S. High Voltage Measurement Techniques, Fundamentals, Measuring Instruments, and Measuring Methods, 1st ed.; Springer International Publishing: Basel, Switzerland, 2019.

36. Farnoosh, R. Brief overview of optical current and voltage sensors in the electric power industry. In NuGrid, Power Corp; NASPI Distribution Task Team: Burnaby, BC, Canada, 2017; Available online: https://www.naspi. org/sites/default/files/2017-06/NuGrid-Optical-Sensors-2017-06-01-v02.pdf (accessed on 26 January 2020).

37. Huang, R.; Duan, Y.; Shi, L.; Liu, B. All-fiber optical current transformer for measuring lightning current. Opto Electr. Eng. 2019, 46, 180363.

38. Yang, F.; Zhang, L.; Li, B. Research on application of new $10 \mathrm{kV}$ high voltage electric energy meter based on all-fiber optical current transformer. In Proceedings of the International Conference on Electrical, Electronics and Mechatronics, Phuket, Thailand, 20-21 December 2015.

39. Bohnert, K.; Frank, A.; Yang, L.; Gu, X.; Müller, G.M. Polarimetric fiber-optic current sensor with integrated-optic polarization splitter. J. Lightwave Technol. 2019, 37, 3672-3678. [CrossRef]

40. He, Z.H.; Li, J.; Ye, Q.Z.; Qi, J.; Liu, Y.B.; Liu, W.-D. Electrical field adjustment test on $500 \mathrm{kV}$ optical metering unit. In Proceedings of the IEEE Power Engineering Society Summer Meeting, Chicago, IL, USA, 21-25 July 2002.

41. Bohnert, K.; Gabus, P.; Brändle, H. Fiber-optic current and voltage sensors for high-voltage substations. In Proceedings of the 16th Conference on Optical Fiber Sensors, Nara, Japan, 13-17 October 2003.

42. Secue, J.R.; Mombello, E. Sweep frequency response analysis (sweep frequency) for the assessment of winding displacements and deformation in power transformers. Electr. Power Syst. Res. 2008, 78, 1119-1128. [CrossRef]

43. Min, L.; Li, S.; Zhang, X.; Zhang, F.; Sun, Z.; Wang, M.; Zhao, Q.; Yang, Y.; Ma, L. The research of vibration monitoring system for transformer based on optical fiber sensing. In Proceedings of the IEEE 3rd Optoelectronics Global Conference (OGC), Shenzhen, China, 4-7 September 2018.

44. Bartoletti, C.; Desiderio, M.; Di Carlo, D.; Fazio, G.; Muzi, F.; Sacerdoti, G.; Salvatori, F. Vibro-acoustic techniques to diagnose power transformers. IEEE Trans. Power Deliv. 2004, 19, 221-229. [CrossRef]

45. Kung, P.; Idsinga, R.; Fu, J.B.; Durand, H.C.V.; Yang, C.S.; Comanici, M.I. Online detection of windings distortion in power transformers by direct vibration measurement using a thin fiber optics sensor. In Proceedings of the IEEE Electrical Insulation Conference, Montreal, QC, Canada, 19-22 June 2016.

46. de Melo, A.G.; Benetti, D.; de Lacerda, L.A.; Peres, R.; Floridia, C.; Silva, A.A.; Rosolem, J.B. Static and dynamic evaluation of a winding deformation FBG sensor for power transformer applications. Sensors 2019, 19, 4877. [CrossRef]

47. Power Transformer Audible Sound Requirements; CIGRE WG A2.54; ELECTRA No 302; CIGRE: Paris, France, 2019; pp. 50-53.

48. Lee, J. Sound detection monitoring in the transformer oil using fiber optic sensor. In Proceedings of the Society of Photo-Optical Instrumentation Engineers on Fiber Optic Sensors and Applications IX, Baltimore, MD, USA, 11 May 2012.

49. Shoureshi, R.; Permana, V.; Wood, R.; Swartzendruber, R.; Simoes, M. Optical Sensor for Transformer Monitoring; Intelligent Substation Final Project Report, PSERC. 2004. Available online: https:// pserc.wisc.edu/documents/publications/reports/2004_reports/T-20_Final-Report_July-2004.pdf (accessed on 26 January 2020).

50. Koch, M.; Tenbohlen, S.; Stirl, T. Advanced online moisture measurement in power transformer. In Proceedings of the International Conference on Condition Monitoring and Diagnosis, Changwon, Korea, 2-5 April 2006. 
51. Harris, D. Condition monitoring in power transformers. In Proceedings of the IEE Colloquium on Condition Monitoring of Large Machines and Power Transformers, London, UK, 19 June 1997.

52. CIGRE Working Group B5.05. Modern Techniques for Protecting, Controlling and Monitoring Power Transformers; CIGRE Report 463; CIGRE: Paris, France, 2011.

53. IEEE Guide for Determination of Maximum Winding-Temperature Rise in Liquid Immersed Transformers; IEEE Std. 1538a-2015 Amend. IEEE Std. 1538-2000; IEEE Standards Association: Piscataway, NJ, USA, 2015; pp. 1-24.

54. Gradnik, T.; Polajner, A. The role of direct hot-spot temperature measurements and dynamic thermal models in the determination of power transformers dynamic thermal rating. In Proceedings of the CIGRE, Paris, France, 26-31 August 2018.

55. Pinet, E.; Ellyson, S.; Borne, F. Temperature fiber-optic point sensors: Commercial technologies and industrial applications. In Proceedings of the MIDEM-Society for Microelectronics, Electronic Components and Materials, Radenci, Slovenia, 29 September-1 October 2010.

56. Bérubé, J.N.; Broweleit, B.L.; Aubin, J. Optimum transformer cooling control with fiber-optic temperature sensors. Electr. Energy T D Mag. 2009, 13, 53-58.

57. Hurezeanu, I.; Nicola, I.C.; Sacerdoţianu, D.; Nicola, M.; Aciu, A.M.; Niţu, M.C. Temperature control and monitoring system for power transformer windings using fiber optic sensors. In Proceedings of the International Symposium on Fundamentals of Electrical Engineering (ISFEE), Bucharest, Romania, 30 June-2 July 2016.

58. Jia, D.; Yao, Z.; Li, C. The transformer winding temperature monitoring system based on fiber Bragg grating. Int. J. Smart Sens. Intell. Syst. 2015, 8, 538-560. [CrossRef]

59. Kweon, D.; Koo, K. Winding temperature measurement in a $154 \mathrm{kV}$ transformer filled with natural ester fluid. J. Electr. Eng.Technol. 2013, 8, 156-162. [CrossRef]

60. Haque, N.; Ittiarah, V.J.; Gangopadhyay, T.K.; Chakravorti, S. Temperature monitoring of power transformer using fiber-optic sensor. In Proceedings of the 1st Conference on Power, Dielectric and Energy Management at NERIST (ICPDEN), Arunachal Pradesh, India, 10-11 January 2015.

61. Gong, R.; Ruan, J.; Chen, J.; Quan, Y.; Wang, J.; Duan, C. Analysis and experiment of hot-spot temperature rise of $110 \mathrm{kV}$ three-phase three-limb transformer. Energies 2017, 10, 1079. [CrossRef]

62. Ukil, A.; Braendle, H.; Krippner, P. Distributed temperature sensing: Review of technology and applications. IEEE Sens. J. 2012, 12, 885-892. [CrossRef]

63. Liu, Y.; Yin, J.; Tian, Y.; Fan, X. Design and performance test of transformer winding optical fiber composite wire based on raman scattering. Sensors 2019, 19, 2171. [CrossRef] [PubMed]

64. Nicola, M.; Nicola, C.; Duţă, M.; Sacerdoţianu, D.; Hurezeanu, I. System for monitoring of hot spot temperature of power transformer windings using fiber optic sensors, Kalman Filter and SCADA integration. In Proceedings of the International Conference on Development and Application Systems (DAS), Suceava, Romania, 24-26 May 2018.

65. Jian-Gang, D.; De-Xin, N.; Ben-Xi, P.; Li, X.; Li, W. Hot-spot temperature and temperature decay rate measurement in the oil immersed power transformer through FBG based quasi-distributed sensing system. Microw. Opt. Technol. Lett. 2017, 59, 472-475.

66. CIGRE Working Group WG D1.01. Report on Gas Monitors for Oil-Filled Electrical Equipment; CIGRE Report 409; CIGRE: Paris, France, 2010.

67. CIGRE Working Group D1/A2.47. DGA Monitoring Systems; CIGRE Report 783; CIGRE: Paris, France, 2019.

68. Bustamante, S.; Manana, M.; Arroyo, A.; Castro, P.; Laso, A.; Martinez, R. Dissolved gas analysis equipment for online monitoring of transformer oil: A review. Sensors 2019, 19, 4057. [CrossRef]

69. Abu-Siada, A. Improved consistent interpretation approach of fault type within power transformers using dissolved gas analysis and gene expression programming. Energies 2019, 12, 730. [CrossRef]

70. Yuan, F.; Guo, J.; Xiao, Z.; Zeng, B.; Zhu, W.; Huang, S. A Transformer fault diagnosis model based on chemical reaction optimization and twin support vector machine. Energies 2019, 12, 960. [CrossRef]

71. Shang, H.; Xu, J.; Zheng, Z.; Qi, B.; Zhang, L. A novel fault diagnosis method for power transformer based on dissolved gas analysis using hypersphere multiclass support vector machine and improved D-S evidence theory. Energies 2019, 12, 4017. [CrossRef]

72. Zeng, B.; Guo, J.; Zhang, F.; Zhu, W.; Xiao, Z.; Huang, S.; Fan, P. Prediction model for dissolved gas concentration in transformer oil based on modified grey wolf optimizer and LSSVM with grey relational analysis and empirical mode decomposition. Energies 2020, 13, 422. [CrossRef] 
73. Transformer Maintenance. Facilities Instructions, Standards, and Techniques (FIST); United States Department of the Interior Bureau of Reclamation: Denver, CO, USA, 2000; Volume 3-30, pp. 1-81.

74. IEEE Guide for the Interpretation of Gases Generated in Oil-Immersed Transformers; IEEE Std. C57.104-2019; IEEE Standards Association: Piscataway, NJ, USA, 2019.

75. Mak, T.; Westerwaal, R.J.; Slaman, M.; Schreuders, H.; van Vugt, A.W.; Victoria, M.; Boelsma, C.; Dam, B. Optical fiber sensor for the continuous monitoring of hydrogen in oil. Sens. Actuators B Chem. 2014, 190, 982-989. [CrossRef]

76. Sun, C.; Ohodnicki, P.R.; Stewart, E.M. Chemical sensing strategies for real-time monitoring of transformer oil: A review. IEEE Sens. J. 2017, 17, 5786-5806. [CrossRef]

77. Dai, J.; Zhu, L.; Wang, G.; Xiang, F.; Qin, Y.; Wang, M.; Yang, M. Optical fiber grating hydrogen sensors: A review. Sensors 2017, 17, 577. [CrossRef] [PubMed]

78. Bodzenta, J.; Burak, B.; Gacek, Z.; Jakubik, W.P.; Kochowski, S.; Urbańczyk, M. Thin palladium film as a sensor of hydrogen gas dissolved in transformer oil. Sens. Actuators B Chem. 2002, 87, 82-87. [CrossRef]

79. Butler, M.; Sanchez, R.; Dulleck, G. Fiber Optic Hydrogen Sensor; Sandia National Laboratories Report SAND96-1133 1 UC-706; United States Department of Energy: Washington, DC, USA, 1996; pp. 1-51.

80. Fisser, M.; Badcock, R.A.; Teal, P.D.; Swanson, A.; Hunze, A. Development of hydrogen sensors based on fiber Bragg grating with a palladium foil for online dissolved gas analysis in transformers. Opt. Meas. Sys. Ind. Insp. X 2017, 10329, 103292P-1-103292P-9.

81. Fisser, M.; Badcock, R.A.; Teal, P.D.; Hunze, A. High-sensitivity fiber-optic sensor for hydrogen detection in gas and transformer oil. IEEE Sens. J. 2019, 19, 3348-3357. [CrossRef]

82. Samsudin, M.R.; Shee, Y.G.; Mahamd Adikan, F.R.; Abdul Razak, B.B.; Dahari, M. Fiber bragg gratings hydrogen sensor for monitoring the degradation of transformer oil. IEEE Sens. J. 2016, 16, 2993-2999. [CrossRef]

83. Dai, J.; Peng, W.; Wang, G.; Xiang, F.; Qin, Y.; Wang, M.; Yang, M.; Deng, H.; Zhang, P. Improved performance of fiber optic hydrogen sensor based on WO3-Pd2Pt-Pt composite film and self-referenced demodulation method. Sens. Actuators B Chem. 2017, 249, 210-216. [CrossRef]

84. Zhang, Y.; Wu, Q.; Peng, H.; Zhao, Y. Photonic crystal fiber modal interferometer with Pd/WO3 coating for real-time monitoring of dissolved hydrogen concentration in transformer oil. Rev. Sci. Instrum. 2016, 87, 125002-125002-6. [CrossRef]

85. Rodriguez, B. Development and Demonstration of New Condition Monitoring Sensors and Techniques; EPRI: Palo Alto, CA, USA, 2009; pp. 1-74.

86. Yan, G.; Ping Zhang, A.; Ma, G.; Wang, B.; Kim, B.; Im, J.; He, S.; Chung, Y. Fiber-optic acetylene gas sensor based on microstructured optical fiber bragg gratings. IEEE Photonics Technol. Lett. 2011, 23, 1588-1590. [CrossRef]

87. Tao, C.; Li, X.; Yang, J.; Shi, Y. Optical fiber sensing element based on luminescence quenching of silica nanowires modified with cryptophane-A for the detection of methane. Sens. Actuators B Chem. 2011, 156, 553-558. [CrossRef]

88. Mishra, S.K.; Tripathi, S.N.; Choudhary, V.; Gupta, B.D. Surface plasmon resonance-based fiber optic methane gas sensor utilizing graphene-carbon nanotubes-poly (Methyl Methacrylate) hybrid nanocomposite. Plasmonics 2015, 10, 1147-1157. [CrossRef]

89. Wu, S.; Zhang, Y.; Li, Z.; Shuang, S.; Dong, C.; Choi, M.M.F. Mode-filtered light methane gas sensor based on cryptophane A. Anal. Chim. Acta 2009, 633, 238-243. [CrossRef]

90. CIGRE, Working Group A2.49. Condition Assessment of Power Transformers; CIGRE Report 761; CIGRE: Paris, France, 2019.

91. Arakelian, V.G.; Fofana, I. Water in oil filled high voltage equipment, Part II: Water content as physicochemical tools for insulation condition diagnosis. IEEE Electr. Insul. Mag. 2007, 23, 15-24. [CrossRef]

92. CIGRE, Working Group D1.52. Moisture Measurement and Assessment in Transformer Insulation-Evaluation of Chemical Methods and Moisture Capacitive Sensors; CIGRE Report 741; CIGRE: Paris, France, 2018.

93. Rodriguez-Rodriguez, J.H.; Martinez-Pinon, F.; Alvarez-Chavez, J.A.; Jaramillo-Vigueras, D. Polymer optical fiber moisture sensor based on evanescent-wave scattering to measure humidity in oil-paper insulation in electrical apparatus. In Proceedings of the IEEE SENSORS, Lecce, Italy, 26-29 October 2008.

94. Laskar, S.; Bordoloi, S. Monitoring of moisture in transformer oil using optical fiber as sensor. J. Photonics 2013, 2013, 528478. [CrossRef] 
95. Zhang, W.; Webb, D.J. PMMA based optical fiber bragg grating for measuring moisture in transformer oil. IEEE Photonics Technol. Lett. 2016, 28, 2427-2430. [CrossRef]

96. Kung, P.; Idsinga, R.; Durand, H.-C.V.; Lu, H.; Kahrizi, M. Fiber optics sensor monitoring moisture transport in oil in an operating transformer. In Proceedings of the IEEE Electrical Insulation Conference (EIC), Baltimore, MD, USA, 11-14 June 2017.

97. Yusoff, S.F.A.Z.; Mezher, M.H.; Amiri, I.S.; Ayyanar, N.; Vigneswaran, D.; Ahmad, H.; Zakaria, R. Detection of moisture content in transformer oil using platinum coated on D-shaped optical fiber. Opt. Fiber Technol. 2018, 45, 115-121. [CrossRef]

98. Akre, S.; Vahid, B.; Peter, K.; Issouf, F. Assessing Water Content and Vibration from Dynamic Measurement in Transformer. In Proceedings of the CIGRE Conference Montréal, Montreal, QC, Canada, 16-19 September 2019.

99. Shi, H.; Chen, W.; Li, X.; Wan, F.; Zhang, S.; Wang, P.; Wang, J.; Zhou, W. Detection of furfural in oil based on surface enhanced Raman spectroscopy. In Proceedings of the IEEE International Conference on High Voltage Engineering and Application (ICHVE), Athens, Greece, 10-13 September 2018.

100. CIGRE, Working Group A2/D1.46. Field Experience with Transformer Solid Insulation Ageing Markers; CIGRE Report 779; CIGRE: Paris, France, 2019.

101. Ahmadi, F.; Zarrin, L.; Sharifnia, S.; Hosseini, S.N. Analyzed and proposed mechanism of photo-catalytic degradation of furfural at $\mathrm{TiO}_{2}$ nanoparticles by HPLC-UV and LC-MASS methods. J. Liq. Chromatogr. Relat. Technol. 2014, 37, 1750-1762. [CrossRef]

102. Jalbert, J.; Gilbert, R.; Tétreault, P.; Morin, B.; Lessard-Déziel, D. Identification of a chemical indicator of the rupture of 1,4- $\beta$-glycosidic bonds of cellulose in an oil-impregnated insulating paper system. Cellulose 2007, 14, 295-309. [CrossRef]

103. Fu, Q.; Zhang, J.; Wang, M.; Chen, T.; Li, J.; Wang, F.; Li, X. Correlation analysis between crystalline behaviour and aging degradation of insulating paper. In Proceedings of the IEEE International Conference on Dielectrics (ICD), Montpellier, France, 3-7 July 2016.

104. Li, J.; Zhang, J.; Wang, F.; Huang, Z.; Zhou, Q. A novel aging indicator of transformer paper insulation based on dispersion staining colors of cellulose fibers in oil. IEEE Electr. Insul. Mag. 2018, 34, 8-16. [CrossRef]

105. Peng, L.; Fu, Q.; Lin, M.; Zhao, Y.; Qian, Y.; Li, S. A novel furfural-detection-method for the aging prediction of paper insulation in power transformer. In Proceedings of the IEEE Conference on Electrical Insulation and Dielectric Phenomena (CEIDP), Cancun, Mexico, 21-24 October 2018; pp. 630-633.

106. Cennamo, N.; De Maria, L.; D’Agostino, G.; Zeni, L.; Pesavento, M. Monitoring of low levels of furfural in power transformer oil with a sensor system based on a POF-MIP platform. Sensors 2015, 15, 8499-8511. [CrossRef] [PubMed]

107. Cennamo, N.; De Maria, L.; Chemelli, C.; Profumo, A.; Zeni, L.; Pesavento, M. Markers detection in transformer oil by plasmonic chemical sensor system based on POF and MIPs. IEEE Sens. J. 2016, 16, 7663-7670. [CrossRef]

108. Zeni, L.; Cennamo, N.; Pesavento, M. Chemical sensors in plastic optical fibers. In Proceedings of the Ninth International Conference on Sensor Device Technologies and Applications, Venice, Italy, 6-20 September 2018.

109. Winders, J. Power Transformers: Principles and Applications; CRC Press: Boca Raton, FL, USA, 2002.

110. Liao, J. Insulating oil level monitoring system for transformer based on liquid level sensor. In Proceedings of the Second International Conference on Digital Manufacturing \& Automation, Zhangjiajie, China, 5-7 August 2011.

111. Mahanta, D.K.; Laskar, S. Power transformer oil-level measurement using multiple fiber optic sensors. In Proceedings of the International Conference on Smart Sensors and Application (ICSSA), Kuala Lumpur, Malaysia, 26-28 May 2015.

112. Kim, T.Y.; Kim, J.E.; Suh, K.S. On-line monitoring of transformer oil degradation based on fiber optic sensors. Sens. Mater. 2008, 20, 201-209.

113. Rao, T.V.; Chakravarthy, V.V.S.S.S.; Murthy, K.K. Working model of optical fiber sensor for estimation of sludge in oil in electrical transformer. Indian J. Pure Appl. Phys. 2011, 49, 596-599.

114. Liu, Y.; Jiang, S.; Fan, X.; Tian, Y. Effects of degraded optical fiber sheaths on thermal aging characteristics of transformer oil. Appl. Sci. 2018, 8, 1401. [CrossRef] 
115. Huang, X.-B.; Xie, C.; Li, H. Equivalent salt deposit density optical fiber sensor for transmission lines in power grid. IEEE Sens. J. 2017, 17, 91-99. [CrossRef]

116. Hao, Y.; Cao, Y.; Ye, Q.; Cai, H.; Qu, R. On-line temperature monitoring in power transmission lines based on Brillouin optical time domain reflectometry. Optik Int. J. Light Elect. Opt. 2015, 126, 2180-2183. [CrossRef]

117. Cirigliano, M.; Cattaneo, G.; Boffi, P.; Barberis, A.; Perini, U.; Pirovano, G.; Martinelli, M. Overhead power lines temperature measurements by a fiber optic Raman sensor. In Proceedings of the 20th International Conference on Optical Fibre Sensors, Edinburgh, UK, 5 October 2009.

118. Benounis, M.; Aka-Ngnui, T.; Jaffrezic, N.; Dutasta, J.P. NIR and optical fiber sensor for gases detection produced by transformation oil degradation. Sens. Actuators A Phys. 2008, 141, 76-83. [CrossRef]

(C) 2020 by the authors. Licensee MDPI, Basel, Switzerland. This article is an open access article distributed under the terms and conditions of the Creative Commons Attribution (CC BY) license (http://creativecommons.org/licenses/by/4.0/). 